\title{
UN NOUVEAU DÉCORATEUR « GÉNIAL » DE LEZOUX ET LA COLLECTION DES MOULES POUR SIGILLÉE GALLO-ROMAINE DU MUSÉE DU LOUVRE
}

\author{
ANDRÁS MÁRTON* - FLORENCE SPECQUE** \\ avec la collaboration d'ESTELLE GAUTHIER*** \\ * Centre de recherche bretonne et celtique \\ 20 Rue Duquesne - CS 93837 \\ 29238 BREST Cedex 3 \\ saxamus@gmail.com
}

**Département des Antiquités grecques, étrusques et romaines, musée du Louvre

Musée du Louvre, 75058 Paris Cedex 01

Documentaliste scientifique

Florence.Specque@louvre.fr

*** Université de Franche-Comté

30-32, rue Megévand, 25030 - Besançon Cedex

estelle.gauthier@univ-fcomte.fr

\begin{abstract}
Moulds and potters' marks are primary sources for our understanding of the relief decorated terra sigillata production. In this paper the Gallo-roman terra sigillata moulds (for relief decorated bowls and goblets) from the collection of the Louvre are presented together with a signed fragment from a relief decorated terra sigillata bowl from Lezoux. Among the moulds several potters' centres are represented: La Graufesenque, Les Martres-de-Veyre, Lezoux and Rheinzabern ranging chronologically from the Trajanic to the Antonine periods. These finds allow a better understanding of workshop activities, individual potter's style and enrich the repertory of motifs and dies used by the decorators. The bowl fragment reveals the name of a Trajanic Lezoux potter Genialis. Based on this fragment, we can hitherto name a previously anonymous Lezoux potter (Potter X-5) and characterise better his activity as one of the early workshop leaders "advertising" himself by large marks stamped into the decoration.

Keywords: Terra sigillata, Central Gaulish potters, Rheinzabern, pottery production
\end{abstract}

À la mémoire de László Horváth (1945-2015)

Le département des antiquités grecques, étrusques et romaines du musée du Louvre conserve une collection de céramiques romaines d'environ 1460 objets entiers ou fragmentaires, essentiellement des sigillées et moules pour sigillées. ${ }^{1}$ Ces objets sont entrés au Louvre principalement dans la deuxième moitié du XIX ${ }^{\mathrm{e}}$ siècle et dans la première moitié du $\mathrm{XX}^{\mathrm{e}}$ siècle. Les acquisitions ont ensuite été beaucoup plus sporadiques. Cet article est consacré à l'étude de onze fragments de moules de sigillée gallo-romaine, qui constituent notre source primaire concernant la production, sélection à laquelle s'ajoute un tesson qui apporte une contribution importante à notre connaissance sur des potiers décorateurs de Lezoux du début du $\mathrm{II}^{\mathrm{e}}$ siècle. ${ }^{2}$

\footnotetext{
${ }^{1}$ Nous souhaitons remercier Madame Cécile Giroire conservateur en chef, en charge des mosaïques, de l'orfèvrerie et des objets d'art romains, pour nous avoir permis d'étudier et de publier ces objets et pour ses précieux conseils lors de la préparation du manuscrit. Nous tenons à remercier Helène Chew, Conservatrice en chef, pour nous avoir permis d'illustrer des moules conservés au Musée d'Archéologie nationale. Nos remerciements vont également à Dr. Nikki Cowlard et Dr. Joanna Bird pour nous avoir permis d'illustrer le bol du Pottier P-20 trouvé à Church Meadow.

Les sigillées conservées au musée du Louvre se distinguent par une grande diversité : «pré-sigillées », italiques, orientales, gauloises, de Rheinzabern, africaines et hispaniques.

${ }^{2}$ Certains de ces moules gallo-romains sont déjà brièvement publiés (RoGERs 1999), mais avec des erreurs et des reproduc-

DOI: $10.1556 / 072.2019 .70 .1 .2$
}

tions parfois trompeuses. Les travaux menés sur la collection nous ont permis de les réétudier.

Pour l'identification des poinçons des moules et du vase gaulois les numéros se réfèrent pour les motifs non figurés au recueil de George Brian Rogers (Rogers 1974), et pour les motifs figuratifs à celui de Felix Oswald (F. OswaLD : Index of Figure-types on Terra Sigillata [«Samian Ware»]. Liverpool 1936-1937). Les numéros commençant par « $\mathrm{R} »$ renvoient aux motifs supplémentaires rassemblés dans RoGers 1999. Certains poinçons ne peuvent pas être retrouvés dans ces recueils, soit parce qu'ils ne sont pas répertoriés, soit parce que la qualité des illustrations n'est pas suffisante. Dans ces cas, nous avons préféré les considérer comme non identifiés tout en donnant une illustration de leurs impressions.

Acta Archaeologica Academiae Scientiarum Hungaricae 70 (2019) 41-66 0001-5210 @ 2019 Akadémiai Kiadó, Budapest 


\section{L'ORIGINE DES CEUVRES}

Le lieu de découverte est renseigné pour quatre objets seulement. Deux proviennent de Gaule. Le moule $\mathrm{n}^{\circ} 1$ a été mis au jour lors des fouilles faites à La Graufesenque (Millau, France) par l'abbé Paulin François Cérès (Rodez, 1814 - Rodez, 1887), conservateur du Musée de Rodez, et a été acquis par le musée du Louvre à une date et dans des circonstances inconnues. Le tesson $\mathrm{n}^{\circ} 12$ a été découvert lors des fouilles de la nécropole romaine de Trion à Lyon, probablement entre 1883 et1885, et est entré dans la collection d'Émile Guimet (Lyon, 1836 - Fleurieu-sur-Saône, 1918) dont les pièces provenant de Gaule et d'Italie ont été transférées au Département des Antiquités grecques, étrusques et romaines du musée du Louvre à une date non déterminée, probablement dans les années $1920 .^{3}$

Le moule $\mathrm{n}^{\circ} 11$ a été découvert, d'après l'étiquette collée sur l'objet, à Rheinzabern (Rhénanie-Palatinat, Allemagne) en 1816. Il provient vraisemblablement des antiquités mises au jour par Lambert de Lauterbourg, administrateur du district de Wissembourg (dès 1815 ou 1816). Une partie de sa collection est entrée à la Bibliothèque publique de Strasbourg ${ }^{4}$ tandis que d'autres œuvres ont été dispersées dans des collections privées. Ce moule serait entré dans la collection du Chevalier Edme-Antoine Durand (Auxerre, 1768 - Florence, 1835). ${ }^{5}$ La première collection d'antiquités de ce dernier est acquise par le Louvre en 1825 et la deuxième par le British Museum à sa mort en $1836 .^{6}$

Le moule lezovien ( ${ }^{\circ} 2$ ) a été acquis de $\mathrm{Ph}$. Emionidis (le 25 juillet 1922), avec un lot d'objets provenant de la nécropole de Samsoun (ou Samsun), dans la région de Trabzon (Trébizonde) sur la mer Noire, en Turquie, pour les départements des Antiquités Orientales et de la Céramique Antique. Toutefois, son rattachement à la production lezovienne rend impossible cette provenance. Ce moule gallo-romain a probablement été mélangé par accident, avant son entrée au Louvre, avec les objets venant d'Asie Mineure.

D'autres moules sont issus de collections privées, sans provenance précise. L'historique des moules $n^{\circ} 3$, 5-7 et 9 est particulièrement intéressant car ils proviennent de la collection du marquis Giovanni Pietro Campana $(1808-1880)$, collectionneur et archéologue italien. ${ }^{7}$

Les quatre moules qui intéressent notre étude sont parmi les rares pièces de la collection Campana provenant de Gaule. Puisqu'ils sont inclus dans les Cataloghi, ${ }^{8}$ il est certain qu'ils ont été découverts avant 1861. Ils figurent probablement parmi les premières sigillées gauloises entrées sur les marchés antiquaires internationaux. Les moules ont été exposés dans les salles du Rhyton sur la via del Babuino. Il semble que Campana les ait collectés pour illustrer la technique de fabrication et qu'il était moins intéressé par leur iconographie. ${ }^{9}$

L'origine des autres objets $\left(n^{\circ} 4,8\right.$ et 10) et leur histoire avant leur entrée dans la collection du musée du Louvre restent inconnues.

Pour le moule de Rheinzabern, les motifs ont été identifiés à l'aide de H. RICKEN-CH. FISCHER: Die Bilderschüsseln der römischen Töpfer von Rheinzabern. Materialen zur römisch-germanischen Keramik 7. Bonn 1963.

Sur la biographie et la collection antique d'Emile Guimet, cf. J.-F. JARRIGE, Émile Guimet (1836-1917) : un novateur et un visionnaire. CRAI 144/4 (2000) 1361-1368 ; G. GALLIANO : Un jour, j'achèterai une momie. Paris-Lyon 2012.

${ }^{3}$ Ce transfert concerne de nombreux objets de céramique d'époque impériale, en particulier, des tessons et moules trouvés sur le site de Pouzzoles en Italie, lors des fouilles de Giuseppe Di Criscio entre 1873 et 1874, ainsi que des tessons issus de Gaule, en particulier de La Graufesenque et de Lezoux (BÉMONT 1977a, 173).

${ }^{4}$ Cf. J.-G. Schweighaeuser : Notice sur les recherches relatives aux antiquités du Département du Bas-Rhin. Strasbourg 1922, 44-45 ; J.-G. SchweIGHAEUSER : Antiquités de Rheinzabern. Strasbourg 1832, 1-2.
${ }^{5}$ Cf. L. Détrez : Edme Antoine Durand (1768-1835) : un bâtisseur de collections, Cahiers de l'École du Louvre 4 (2014) 45-55.

${ }^{6}$ A leur arrivée au musée du Louvre, les objets sont inscrits sur un registre et reçoivent un numéro précédé des lettres ED. Dans le chapitre 17 du livre ED, intitulé « vases romains », les deux fragments, ED 1420 et ED 1421 non encore rassemblés, font partie d'un lot de « trois fragments de moules antiques ». C'est sous Napoléon III, en 1852, que l'objet est recomposé à partir de ces deux fragments jointifs, et qu'un numéro d'inventaire, N 4366, lui est donné. Le troisième fragment est aujourd'hui perdu.

${ }^{7}$ Sur 1'acquisition de la collection Campana, cf. G. NADAlini : La collection Campana au musée Napoléon III et sa première dispersion dans les musées français (1862-1863). Journal des Savants (1998) 183-225 ; GAULTIER et al. 2018.

${ }^{8}$ Cataloghi Campana, ${ }^{\circ}$ 34-36, 42, 45.

${ }^{9}$ S. SARTI: Giovanni Pietro Campana 1908-1880. The man and his collection. BAR IntSer 971. Oxford 2001, sur les moules, spécialement 79 . 


\section{ÉTUDE CÉRAMOLOGIQUE}

1. Fragment de moule pour bols à reliefs de forme Drag. 37 (fig. $1.11 ; 2.1-2 a-b$ ).

Inv. : CA 6374. Trouvé à La Graufesenque, lors des fouilles de l'Abbé Cérès en 1883 (?) ; ancien fonds, inventorié en 1975. Dim : 5,9 $98,5 \mathrm{~cm}$. Haut. max. du moule : $2,4 \mathrm{~cm}$. Diam. reconstitué du pied annulaire $: 5 \mathrm{~cm}$.

Bibl. : P. F. CÉRÈs : Deux poteries couvertes de grafittes, trouvées par ce savant à la Gros-fesenque, commune de Millau (Aveyron). BSAF (1884) 83-85, 84 et fig. ; P. F. CÉRÈS : Compte-rendu de fouilles archéologiques, fouilles à La Graüfesenque, près Millau. Mémoires de la Société des Lettres, Sciences et Arts de l'Aveyron 13 (1881-1886) [1886] 198-203, 202-203 et ill. ; BÉMONT 1977a, 192-193, nº 303, fig. 8 ; MeEs 1995, 170, nº 2, pl. 162,2 ; Names 1,278, MS1 et fig.

Argile de couleur saumon avec des petites inclusions calcaires. Fragment de fond d'un moule hémisphérique, avec pied. A l'intérieur et à l'extérieur, des concrétions.

Le fond, tournassé à l'intérieur du pied, est concave et se sépare du pied par un sillon. Le bord du décor estampé est conservé : une petite partie d'une couronne composée de feuilles (?), délimitée en partie inférieure par une ligne. Sous la ligne, une signature cursive faite ante cotturam : GatPas.

Connu depuis longtemps, ce fragment appartenait au seul moule conservé de ce décorateur. Par comparaison avec d'autres fragments de vases signés du potier $G() A t.() P a s.($.$) il est probable que ce fragment de moule était$ décoré de métopes ou de rinceaux libres. ${ }^{10}$

La signature cursive correspond probablement aux tria nomina :G(.) At(.) Pas(.) d'un potier tardif, fabricant et décorateur de moules, ${ }^{11}$ de La Graufesenque dont on peut situer l'activité entre 90/100-120. ${ }^{12}$

\section{Fragment de moule pour bols à reliefs de forme Drag. 37 (fig. 1.7 ; 3. 1-6).}

Inv. : CA 2532. Acquis par le musée du Louvre en 1922 de Ph. Emionidès avec les objets trouvés à Samsoun. Haut. max. : 10,3 cm. Larg. max. : 8,3 cm. Diam. reconstitué du moule : cca. $27 \mathrm{~cm}$.

Bibl. : ROGERS 1974, 97, G290, 113, H122 ; ROGERS 1999, 310, nº 8, pl. 131. 8.

Argile brun clair avec un peu d'inclusions calcaires. Fragment d'un moule hémisphérique avec une encoche sous le bord ; à l'extérieur, une encoche pour faciliter sa manipulation. Décor très net, moule peu usé.

Décor en métopes délimitées sur les côtés par une ligne ondulée fermée en haut et en bas par une petite rosace à cercle central et à sept pétales. Oves encadrés en haut et en bas par une ligne ondulée. Dans la première métope partiellement conservée : un personnage barbu tourné à gauche sous une double arcature, fermée à droite et en partie inférieure par une ligne ondulée ; au-dessous, deux torsades estampées à angle droit ; accolées aux torsades, spirales sans doute disposées d'une façon symétrique dans la composition originelle ; à droite du personnage barbu, une rangée de neuf petites feuilles doubles dans un cadre formé par des lignes ondulées (dont les intersections en bas sont décorées par la même rosace à cercle central et sept pétales) et en haut par une torsade. Sur cette torsade en angle droit, une courte ligne ondulée terminée par une feuille trifide. Entre cette feuille et le double arceau, une petite feuille double. Deuxième métope fragmentaire, ornée d'une sirène jouant de l'aulos, tournée vers la droite, inscrite dans un cercle double entouré par une couronne composée de petites feuilles doubles et fermée par une rosace. Dans les angles communs avec la métope précédente, en bas et en haut, une feuille (estampée avec des poinçons différents) à l'extrémité d'une tige recourbée ; près de chaque feuille, une petite feuille double. La composition devait être symétrique de l'autre côté du médaillon, aujourd'hui cassé, comme en témoigne la petite feuille double estampée en bas. Le décor est fermé en bas de la panse par une couronne composée de feuilles tripartites dirigées vers la droite, bordée en haut par une ligne de perles.

Certains poinçons attestés sur le moule comme l'homme barbu, la sirène avec aulos, le grand cercle double, la torsade et peut-être la feuille double de la couronne semblent être des poinçons non répertoriés. ${ }^{13}$

\footnotetext{
${ }^{10}$ Par ex. MeEs 1995, 162. 1 et 7. Pour des rinceaux libres : MeEs 1995, 162. 6 ; La Graufesenque, Dépôt de Fouilles, G71 A55-1 (Samian.net $n^{\circ}$ 2003327) ; La Graufesenque, Dépôt de Fouilles, Coll. Artières (Samian.net $n^{\circ}$ 2003328).

${ }^{11}$ HaAlebos - Mees - Polak 1991, 81

${ }^{12}$ MeEs 1995, 90, daté entre 90/100-120 ; Names 1, 278, avec une datation entre 80-110; Names 7, 12.
}

${ }^{13}$ Motifs figurés : Pan type O719 (?). Motifs non figurés : ligne de perles : A5 ; ligne ondulée : A23 ; oves : B8 ; rosace : C141 ; feuille tripartite de la couronne en bas : G25 ; petite feuille double : G29 ; petite feuille tripartite lancéolée : G338 (?) ; grande feuille : H122 ; grande feuille lancéolée : J103 (?) ; spirale : S54. Motifs non répertoriés : homme barbu, sirène avec aulos, grand cercle double, feuille double de la couronne, torsade. 


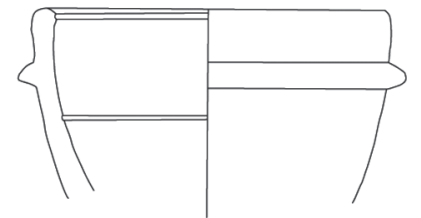

Cp 4827

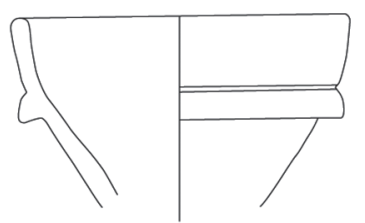

CA 2240

2

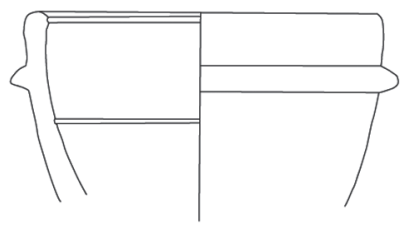

Cp 4833

3

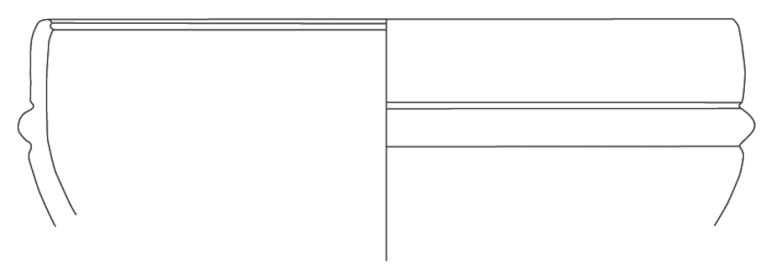

Cp 4826

4

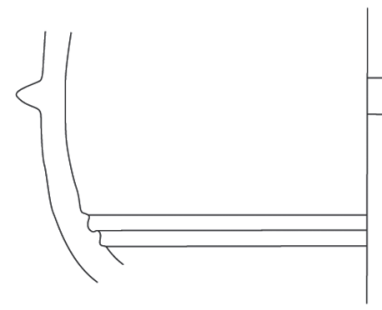

Cp 4831

5

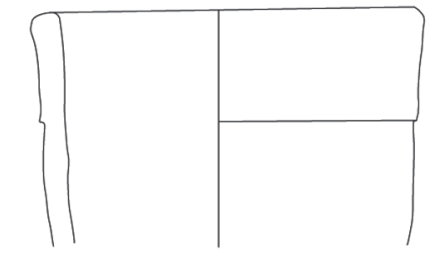

CA 2239

6
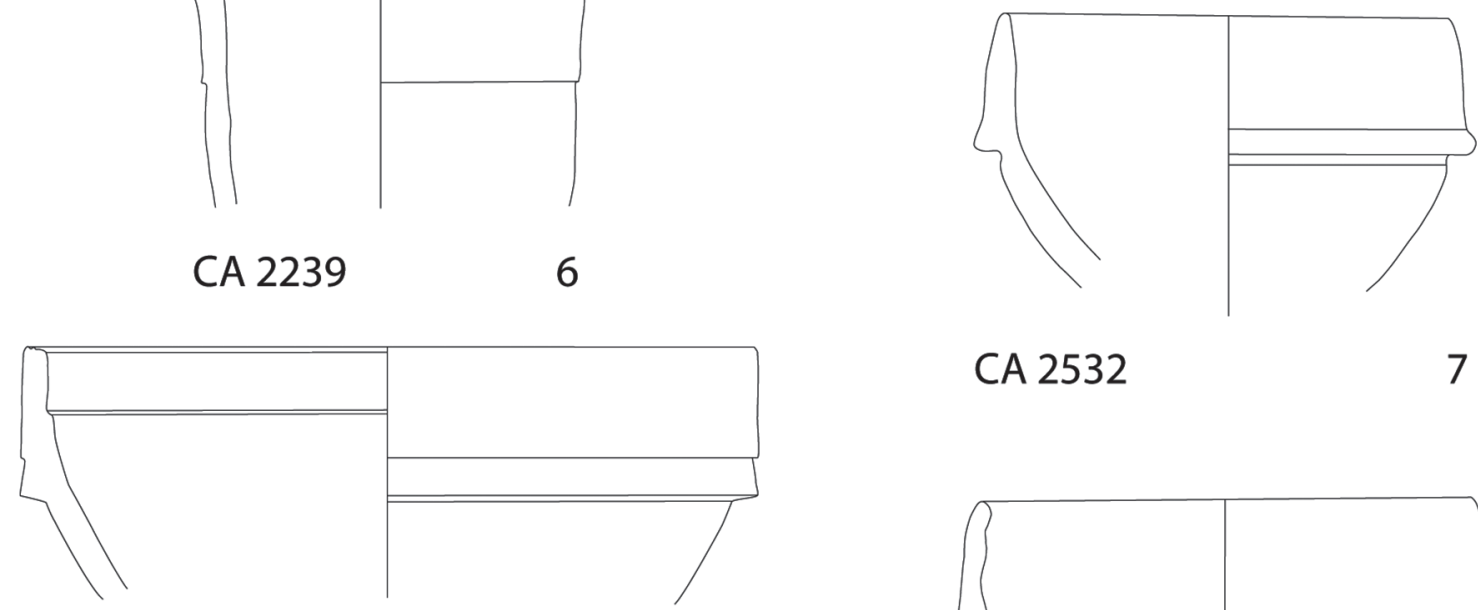

Cp 4835

8

CA 2532

7

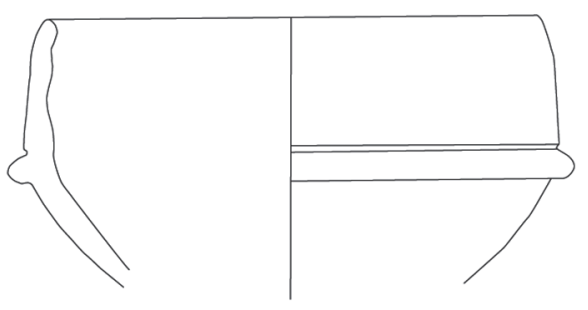

CA 2238

9
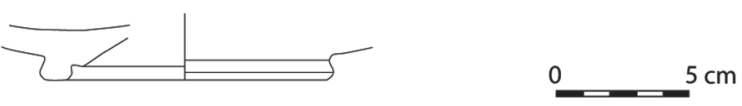

ED 1420-1421

10

CA 6374

11

Fig. 1. Profils des moules, (C) musée du Louvre/András Márton 


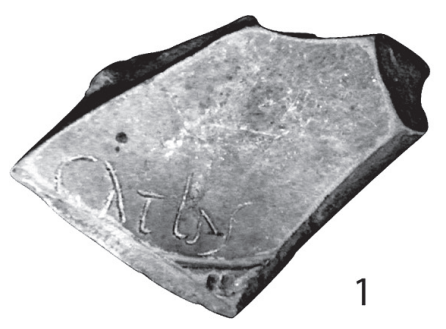

0

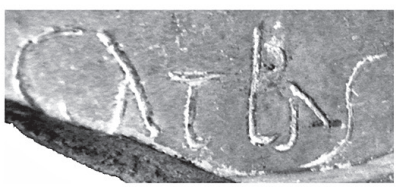

$2 a$

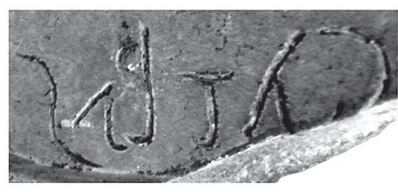

$2 b$

0

$5 \mathrm{~cm}$

Fig. 2. Moule Louvre $n^{\circ}$ CA 6374. 1. vue complète et 2. détail : photographie directe du moule (a) et positif qui pourrait en être tiré (b), (C) musée du Louvre/András Márton

Ce moule est paru dans la monographie de Brian Rogers, mentionné par erreur comme bol connu d'après un moulage conservé à Monaco. ${ }^{14} \mathrm{Il}$ a été attribué avec raison au Potier X-0, l'un des potiers les plus anciens de la phase «classique » de la production de sigillée à Lezoux. ${ }^{15}$ Son style est fortement influencé par la sigillée sud-gauloise, notamment de La Graufesenque, surtout celle de Germanus i. Il est possible qu'il fût formé dans son entourage.

L'activité de ce potier anonyme est datée par des critères stylistiques entre la fin de l'époque flavienne et la première moitié du règne de Trajan, vers $90-110 .^{16}$

\section{Fragment de moule pour gobelets à reliefs (fig. $1.1 ; 4.1-4$ ).}

Inv. : Cp 4827 (H 480). Ancienne collection Campana acquise en 1861 par le musée du Louvre. Dim. : Haut. max. : $8 \mathrm{~cm}$. Larg. max. : 12,2 cm. Diam. reconstitué du moule : $14 \mathrm{~cm}$.

Bibl.: Cataloghi Campana, no 42 ; L. OHLENRoth : Fälschungen von Popilius-Lappius-Bechern aus Originalmodeln. RCRF Acta 2 (1959) 29-39, 33, nº 2 ; SIMPSON 1971, 89-91, fig. 1 ; BÉMONT 1977b, 14, Tab. IV, avec $\mathrm{n}^{\circ}$ inv. erroné.

Argile brun clair avec de très petites inclusions calcaires. Fragment de la panse du moule conservée sur environ un tiers. Dépôts calcaires sur les deux faces.

Moule à cordon de forme ovoïde, plutôt hémisphérique vers le haut, rétréci vers le bas. A l'extérieur sous le bord, un profil triangulaire, légèrement arrondi pour faciliter la manipulation du moule. A l'intérieur, une décoration en métopes séparées par une ligne de perles rythmée par trois peltes et délimitées par une ligne horizontale en haut et en bas : candélabre ; Pan en vue frontale avec jambes croisées et un masque féminin entre les jambes, imprimé horizontalement regardant vers le haut ; feuille d'acanthe estampée sur un rinceau (large spirale) partant de deux petits dauphins estampés sur la ligne d'encadrement en bas. Certains des poinçons utilisés pour ce décor ne peuvent pas être identifiés et pourraient être des motifs non répertoriés. ${ }^{17}$ Ces trois métopes ont probablement été répétées trois fois sur le gobelet.

Dr. Grace Simpson a identifié le moule comme ayant servi pour la fabrication de gobelets de forme Déchelette 68, mais sa forme indique plutôt un gobelet de forme Déchelette 67. Contrairement au dessin erroné de la figure de Pan, il s'agit bien du type O719. L'impression a peut-être été faite par un poinçon endommagé ; la main gauche levée avec la couronne manque (pourtant la figure est profondément imprimée). La plupart des poinçons utilisés pour ce décor sont des créations de l'époque de Trajan, mais comme G. Simpson l'a déjà observé, le candélabre est une création de l'époque d'Hadrien qui situe la réalisation du moule sous Hadrien ou Antonin le Pieux. ${ }^{18}$ S'il s'agit vraiment d'un poinçon endommagé, dans le cas de notre Pan, il peut être considéré comme un autre indice pour la datation de la fabrication de ce moule. Pour le moment, le potier le plus récent pour lequel son utilisation est prouvée est Acaunissa, actif entre 125 et 150. Sur ses vases, le poinçon est intact. La figure apparaît aussi sur un fragment

${ }^{14}$ Rogers 1999, 310.

${ }^{15}$ Sur le Potier X-0, cf. Rogers 1999, 310-311 et NORMAND 2009, 39, Décor 5-7, fig. 3, avec des décors et des poinçons inédits pour ce potier.

${ }^{16}$ Rogers 1999, 311.
${ }^{17}$ Motifs figuratifs : Pan : D421 = O719 (Acaunissa - Valenus I, Drusus I, X-2). Motifs non figuratifs : acanthe : K13 (Drusus I et Me[---) ; pelte : U129 (Acaunissa, Ioenalis, Medetus, Ranto, Sacer, X-8, X-9, X-11). Motifs non identifiés : masque, petits dauphins, ligne de perles, candélabre et grande spirale.

${ }^{18}$ Simpson 1971, 90. 
non signé mais attribué à Atilianus (160-200), ${ }^{19}$ elle semble intacte, mais plus petite et l'avant-bras tenant la couronne est également plus court. On ne peut pas exclure qu'il ne s'agisse pas d'un autre poinçon similaire ou d'un poinçon tiré d'un surmoulage et complété après l'endommagement du poinçon original du Pan O719. ${ }^{20}$

Le style du décor et les poinçons utilisés indiquent que ce moule pourrait avoir été réalisé vers la fin de l'époque d'Hadrien ou sous Antonin le Pieux, par un potier ayant appris son métier dans l'entourage d'Acanuissa. D'après la qualité de la pâte et les poinçons utilisés, ce moule a probablement été fabriqué dans un atelier des Martres-de-Veyre.

4. Fragment de moule pour gobelets à reliefs (fig. 1.2. 1-4).

Inv. : CA 2240. Prov. inconnue, acquis par le musée du Louvre en 1919. Haut. max: 7,8 cm ; Larg. max.: $12 \mathrm{~cm}$. Diam. reconstitué du moule : $13,6 \mathrm{~cm}$.

Bibl. : SiMPSON 1971, 90-91, fig. 2, avec un dessin inversé ; BÉMONT 1977b, 14, Tab. IV.

Argile brun clair, cuite dure, légèrement micacée. Fragment de la panse du moule, conservé sur un tiers environ. Dépôts calcaires sur les deux faces.

Moule à cordon de forme ovoïde, élancé, conçu pour la fabrication de gobelets de forme Déchelette 68 . Il s'agit d'une variante tardive de ce type de matrice, avec une bordure verticale, soulignée par un bourrelet peu saillant à facettes. A l'intérieur, un décor en métopes séparées par une ligne de perles fermée en haut et en bas par une rosace à quatre pétales. La zone décorée est délimitée en haut et en bas par une ligne horizontale. Elle comprend : un dauphin dans un double arceau fermé par des astragales reliés à la ligne de perles et sous l'arceau, une grande composition de feuilles ; superposition de deux doubles cercles contenant pour l'un, deux petits dauphins, et pour l'autre, un panier ou cratère mal imprimé (?), et séparés une petite composition de feuilles encadrée par deux petits cercles. Au centre du fragment, un assemblage composé d'une torsade, d'une colonne et d'une terminaison trifide au milieu d'une composition en croix formée par des lignes ondulées. ${ }^{21}$

On ne peut pas attribuer le style de ce décor à un potier déjà identifié, il est probable que le décorateur ait travaillé dans l'entourage d'Aduocisus.

Dr. Grace Simpson a daté ce moule de l'époque d'Hadrien. Parmi les poinçons employés se trouvent des créations de l'époque de Trajan et de la fin du règne d'Hadrien ou d'Antonin le Pieux. La forme du moule indique une datation un peu plus tardive..$^{22} \mathrm{La}$ fabrication de ce moule pourrait se situer entre 140 et 180 dans un atelier de Lezoux, d'après les indications données par les poinçons et les caracteristiques de la pâte.

5. Fragment de moule pour bols à reliefs de forme Drag. 37 (fig. 1.4; 6. 1-5).

Inv. : Cp 4826 (H 479). Ancienne collection Campana acquise en 1861 par le musée du Louvre. Haut. max : $7,7 \mathrm{~cm}$; Larg. max. 8,3 cm. Diam reconstitué du moule : $27-28 \mathrm{~cm}$.

Bibl. : Cataloghi Campana, ${ }^{\circ} 34$; Rogers 1999, 209, nº 37, pl. 94. 37.

Argile brun clair, avec quelques micas. Fragment d'un moule hémisphérique, de gros éclats sur le bord. Trou moderne sur le bord supérieur, trois étiquettes sur la paroi externe, trace de cire à l'intérieur qui maintenait une étiquette aujourd'hui perdue. Dépôts calcaires.

Le bord du moule est arrondi. A l'extérieur, une encoche pour faciliter sa manipulation. A l'intérieur, un sillon sous le bord puis la zone décorée : une frise d'oves délimitée par une ligne ondulée surmontant une scène de venatio : un gladiateur (tyrannicide) à gauche attaqué par un chien dont ne subsistent que la tête et l'avant-train, et un lion bondissant vers la gauche au dessus d'un personnage tombé à terre. Les deux scènes sont séparées par un candélabre, surmonté par un oiseau, tous deux estampés sur une ligne ondulée. Dans le champ, une petite feuille double. ${ }^{23}$

\footnotetext{
${ }^{19}$ Rogers 1999, 50, fig. 7. 3.

${ }^{20}$ Hélas la qualité de l'illustration ne permet pas de trancher sur cette question.

${ }^{21}$ Motifs figurés : dauphin : O2401 (Doeccus, Pugnus, Cinnaus, Secundus). Motifs non figurés : terminale trifide : G73 ? (Aduocisus, Iullinus, P. X-14); feuille : L1 (Aduocisus, Antistii, Borillus, Cinnamus, Pugnus II) ; petite composition de feuilles : U106? (Aduocisus, X-8 avec Medetus et Ranto, Tasgillus I) ; torsade peutêtre U117 (Aduocisus, Censorinus, Divixtus). Motifs non identifiés

(nouveaux poinçons ?) : colonne, ligne ondulée, ligne de perles (A2 ?), double cercle, petit cercle.

${ }^{22}$ Cf. BÉmONT 1977a, 33-35.

${ }^{23}$ Motifs figurés : Lion : O1497z ? (Bassus, Quintilianus I) ; tyrannicide : O188 (Albucius, Avitus, Caletus, Geminus, Paternus II, Pugnus, Sissus II, P-14, Rosette). Motifs non figurés : ove : B28 (Drusus I, Drususus, Ianuaris I cursive sur Quintilianus, Me..., Mercator I, Paterclus cursive sur Quintilianus I, Quintilianus I, Rentus/Secundinus V, Sissus I, X-2) ; candélabre : Q84 (Ianuaris I cursive sur Quintilianus, 

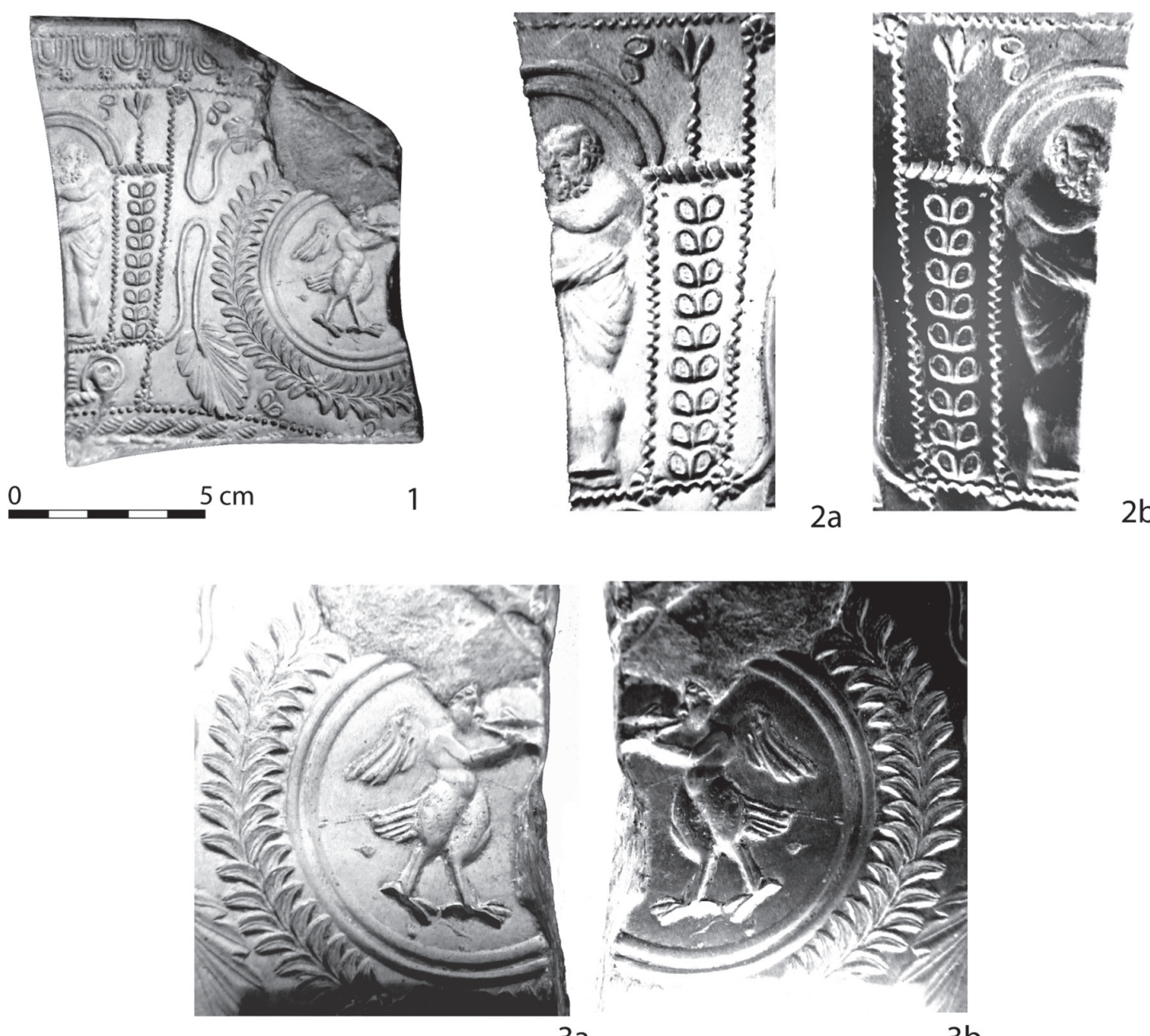

$3 a$

$3 b$
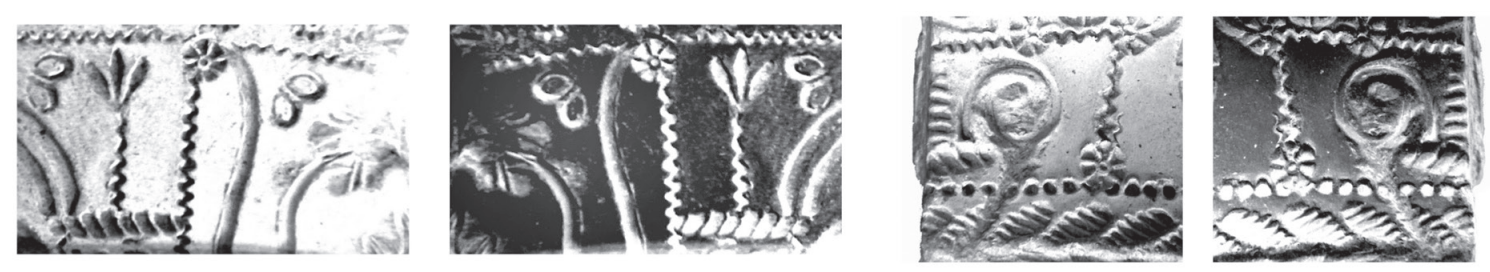

$4 a$

$4 b$

$5 a$

$5 b$
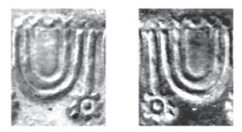

$6 a$

$6 \mathrm{~b}$

0 $5 \mathrm{~cm}$

Fig. 3. Moule Louvre $n^{\circ}$ CA 2532. 1. vue complète, 2-6. détails : a. photographie directe du moule (a) et positif qui pourrait en être tiré (b), (c) musée du Louvre/András Márton 

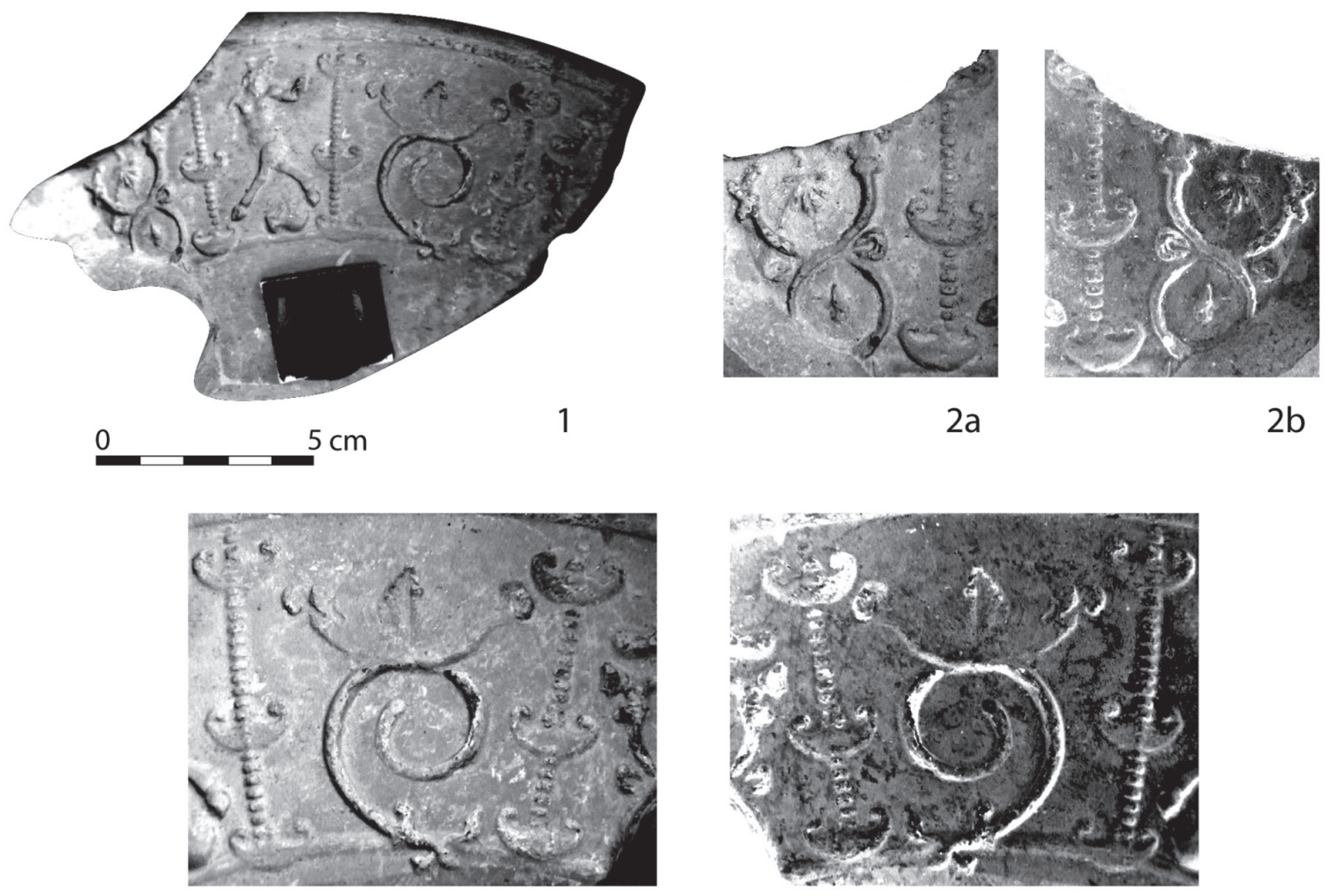

$3 a$

$3 b$

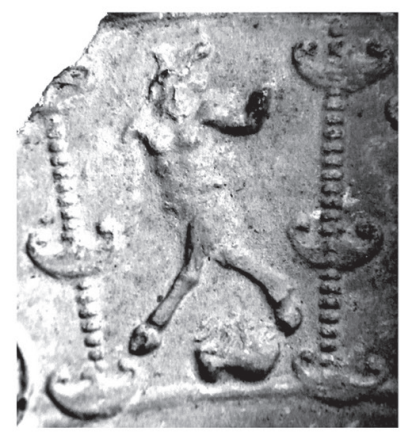

$4 a$

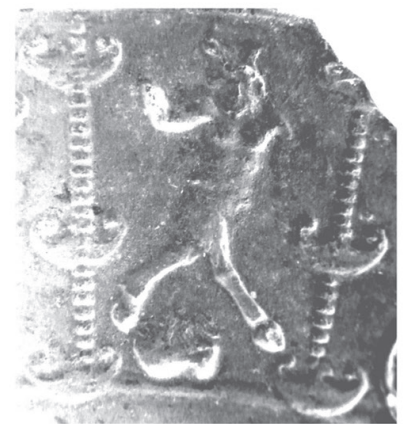

4b

Fig. 4. Moule Louvre ${ }^{\circ} \mathrm{Cp}$ 4827. 1. vue complète, 2-4. détails : a. photographie directe du moule (a) et positif qui pourrait en être tiré (b), (C) musée du Louvre/András Márton

Dans l'ouvrage de Brian Rogers, ce moule est publié par erreur comme fragment de bol et est attribué au groupe de Quintilianus (ou plus exactement à l'atelier de Quintilianus I). ${ }^{24}$ Le fragment de moule du Louvre se rapproche d'un autre exemplaire sans numéro du Musée d'Archéologie nationale, ${ }^{25}$ peut-être réalisé par le même potier et décoré dans le style de Paterclus/Doeccus II.

L'atelier de Quintilianus était actif à Lezoux, entre 125 et $150 .^{26}$

Paterclus cursive sur Quintilianus I, Plautinus, Quintilianus I, Sissus II), double feuille : G303 (Avitus, Paterclus cursive sur Quintilianus I). Motifs non identifiés (nouveau poinçons ?) : Diane (?), chien, oiseau. Acta Archaeologica Academiae Scientiarum Hungaricae 70, 2019

\footnotetext{
${ }^{24}$ Cf. Stanfield - Simpson 1990, 186.

${ }^{25}$ Rogers 1999, pl. 93. 27.

${ }^{26}$ STANFIELD - SiMPSON 1990, 190 ; Rogers 1999, 210.
} 
6. Fragment de moule pour bols à reliefs de forme Drag. 30 (fig. 1.3 ; 7. 1-5).

Inv. : Cp 4833 (H 481). Ancienne collection Campana acquise en 1861 par le musée du Louvre. Haut. max : 7,5 cm ; Larg. max. 9,6 cm. Diam reconstitué du moule : cca. $17 \mathrm{~cm}$.

Bibl. : Cataloghi Campana, no 45 ; Rogers 1999, 209, nº 39, pl. 94. 39 ; GAULTIER et al. 2018, 245, nº 261 et coul. fig.

Argile cuite brun clair, brun rosé avec quelques calcaires et micas. Fragment de moule cylindrique. Trou moderne sous le bord, étiquette collée à l'intérieur et à l'extérieur. Surface usée avec des concrétions.

Paroi cylindrique ; bord arrondi, avec une encoche plate à l'extérieur. A l'intérieur, frise d'oves délimitée par une ligne ondulée, sirène dans un double arceau (lisse à l'intérieur, segmenté à l'extérieur), entre deux compositions florales (celle de gauche est lacunaire) formées chacune par une feuille lanciforme posée sur une rangée de feuilles doubles allongées avec des lignes ondulées descendant des feuilles supérieures. Sous le double arceau, dans le champ, deux rosaces composées de points entre lesquelles, on distingue, un peu plus bas, une rosace au sommet d'une composition florale (?). ${ }^{27} \mathrm{Il}$ s'agit probablement d'un moule usé.

Brian Rogers publie par erreur ce moule, ayant servi pour la fabrication de bols à reliefs de forme Drag. 30, comme un fragment de vase mais l'a justement attribué au Groupe de Quintilianus I (ou mieux, à l'atelier de Quintilianus I) ${ }^{28}$ Les motifs utilisés placent ce moule clairement dans la production de cet atelier. Bien que plus soigné et plus régulier, son décor évoque le style de Paterclus/Doeccus I.

L'atelier de Quintilianus I était actif à Lezoux, entre 125 et $150 .^{29}$

7. Fragment de moule pour bols à reliefs de forme Drag. 37 (fig. $1.5 ; 8.1-4 ; 9.1-3$ ).

Inv. : Cp 4831 (H 477). Ancienne collection Campana acquise en 1861 par le musée du Louvre. Haut. max. : 1,2 cm. Larg. max. $12,6 \mathrm{~cm}$

Bibl. : Cataloghi Campana, no 36 ; Rogers 1999, 195, pl. 83. 9, avec nº inv. erroné, dessin inversé ; GAULTIER et al. 2018, 245, $\mathrm{n}^{\circ} 260$ et coul. fig.

Argile cuite brun, brun-rosé, un peu micacée. Sur le moule : 12.S.18.4. Fragment d'un moule hémisphérique avec une encoche sous le bord, à l'extérieur, une encoche pour faciliter sa manipulation. Trace de cire à l'intérieur qui maintenait une étiquette aujourd'hui perdue.

Restes de deux oves délimités par une ligne de perles. La décoration en panneaux est fermée en bas par deux sillons et compartimentée par des lignes de perles terminées par des rosaces à sept pétales : à gauche, restes d'un double arceau contenant un motif non identifié ; dans le panneau au dessous, deux rameaux courbes ; au centre, une protomé de chien tournée à droite inscrite dans un double cercle, au dessous, un hippocampe ; à droite dans un grand panneau, restes d'une nymphe avançant vers la gauche et tenant son manteau. Vers le milieu de la ligne de perles devant la nymphe, l'impression d'un bouclier se superpose à l'impression partielle du poinçon de rameau courbe. ${ }^{30}$

Ce fragment de moule a été, à juste titre, attribué par B. Rogers à Plautinus, un potier possédant un style bien reconnaissable et homogène. Les dessins publiés suggèrent que ce fragment complète un moule de la collection du Musée d'Archéologie nationale, ${ }^{31}$ mais d'après une comparaison de visu, il est clair que les deux fragments ne recollent pas.

Plautinus, qui était le successeur de Libertus, n'est connu pratiquement que par ses moules (fig. 8-10). ${ }^{32}$ Etant donné le faible nombre de vases qui lui sont attribués, il est vraisemblable que sa production fut peu volumineuse et de courte durée.

${ }^{27}$ Motif figuré : sphinge : similaire au type O863, mais non identique. Motifs non figurés : ove : B28 (Drusus I, Drususus, Ianuaris I cursive sur Quintilianus, Me..., Mercator I, Paterclus cursive sur Quintilianus I, Quintilianus I, Rentus/Secundinus V, Sissus I, X-2) ; feuille lanciforme : J41 (Iuliccus I, Laxtucissa, Priscinianus, Quintilianus I) ; double arceau : F32 (Avitus, Butrion Priscinianus, Quintilianus I, Sissus I, Sollemnis), rosace : Stanfield - Simpson 1990, 188, fig. 17. 15 ; rosace de points : STANFIELD - SiMPSON 1990, 188, fig. 17. 6. Motif non identifié : ligne ondulée.

${ }^{28}$ Cf. STANFIELD - SiMPSON 1990, 186.

${ }^{29}$ STANFIELD - Simpson 1990, 190 ; Rogers 1999, 210.

${ }^{30}$ Motifs figuratifs : nymphe : O347, poinçon cassé (?) ; hippocampe : type $\mathrm{O} 32$ (poinçon non identique) ; chien : similaire

mais non identique à 01934 (!). Motifs non figuratifs : ove : B206 (?) ; rameau courbé : H117 ; petite rosette : C281 ; double arceau : type F32 (même poinçon ?) ; bouclier : type U55 (poinçon ?).

${ }^{31}$ Rogers 1999, pl. 84. 15.

${ }^{32}$ La plupart de ces moules ont été découverts dans un four, près de l'atelier de Libertus, à Lezoux lors des fouilles du docteur Plicque. Ils sont conservés au Musée d'Archéologie nationale (excepté un, aujourd'hui à Avignon), cf. M. R. HÉron DE VILlefossE : Campagne des fouilles faites à Lezoux (Puy-de-Dôme) par le docteur Plicque. Bulletin de la Société des Antiquaires de France (1883) 8990, 89. Sur Plautinus, cf. BÉMONT 1977a, 150-152, fig. 55. P 614 détails de Rogers 1999, pl. 83. 12 et PM 409 (moule non inclus dans Rogers 1999) ; sur la relation entre Libertus et Plautinus, cf. 

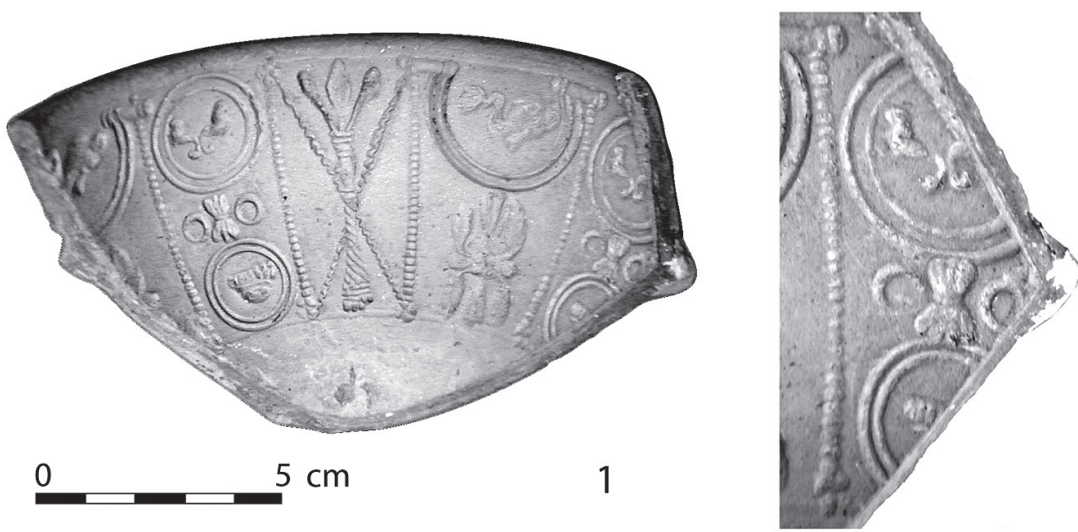

$2 a$
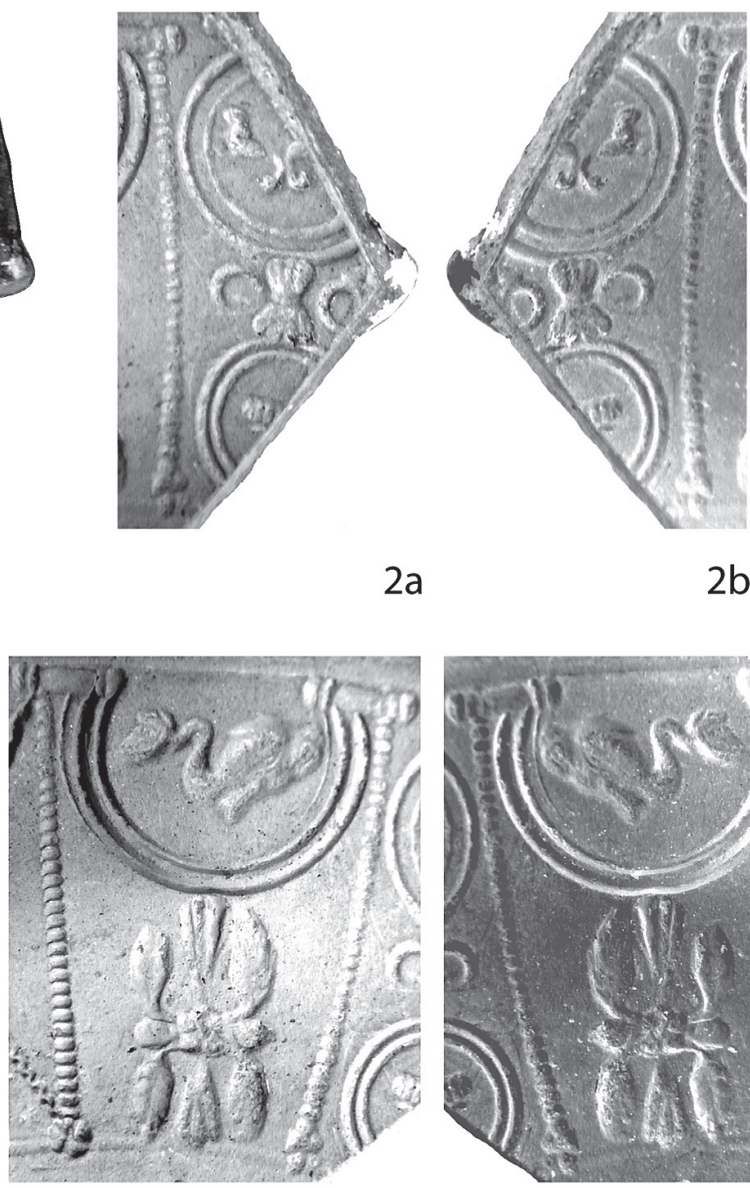

$4 a$

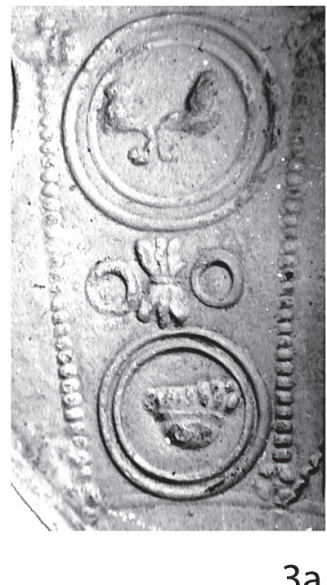

$3 a$

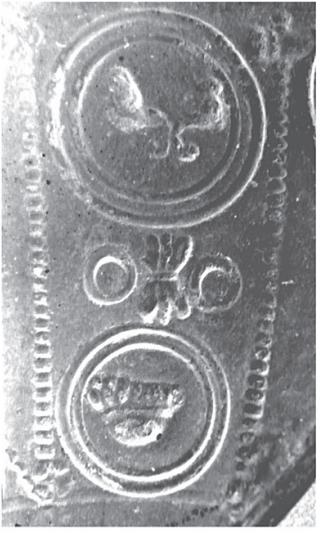

$3 b$
$2 b$

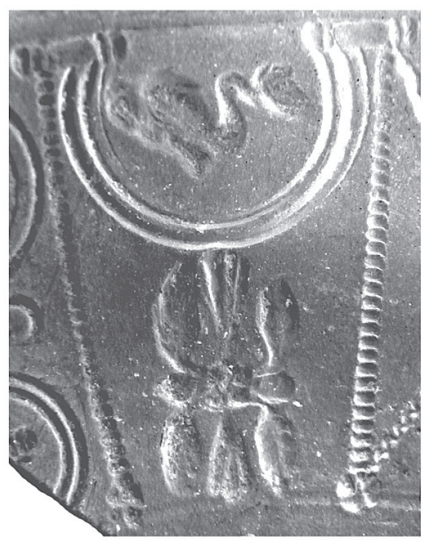

$4 b$

$5 \mathrm{~cm}$

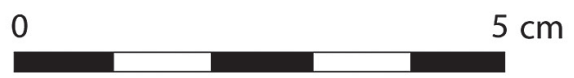

Fig. 5. Moule Louvre ${ }^{\circ}$ CA 2240. 1. vue complète, 2-4. détails : a. photographie directe du moule (a) et positif qui pourrait en être tiré (b), (C) musée du Louvre/András Márton

Pour le moment, aucun de ses vases n'est issu d'un contexte bien datable. On peut situer son activité à Lezoux, d'après des critères stylistiques et les formes lisses signées par Plautinus, entre 150 et 175 (?). ${ }^{33}$

8. Fragment de moule pour bols à reliefs de forme Drag. 30 (fig. $1.6 ; 11.1-4$ ).

Inv. : CA 2239. Prov. inconnue, acquis par le musée du Louvre en 1919. Haut. max. : 9 cm. Larg. max. : $7,8 \mathrm{~cm}$. Diam. reconstitué du moule : 13,6 cm. Moule légèrement usé.

Bibl. : Rogers 1974, 42, B46, 130, J 146 ; Rogers 1999, 292, fig. 77. 5, dessin inversé.

Pâte brun clair, légèrement micacée, poreuse, mal cuite ; cuite gris clair à l'intérieur.

C. BÉmONT - G. B. Rogers : Libertus (ou Liberti ?). II. : Le style aux graffites. Gallia 37/1 (1979), 141-200 ; RoGERs 1999, 194-196, pl. 83-81. Le recueil de G. B. Rogers peut être complété par une série de fragments de moules inédits, non inventoriés, dans la collection du Musée d'Archéologie nationale illustrés sur la figure $10: 1-2,7$. appartiendraient au moule Rogers $n^{\circ} 15$; 8. Inédit cf. Rogers n ${ }^{\circ} 24-25$;
9. appartiendrait au moule Rogers $\mathrm{n}^{\circ} 24 ; 13$. inédit cf. Rogers $\mathrm{n}^{\circ} 20$ 21. inédit cf. Rogers $n^{\circ} 1 ; 22$. inédit cf. Rogers $n^{\circ} 19 ; n^{\circ} 24$ identique ? à Rogers $n^{\circ} 18 ; 27$. inédit cf. Rogers $n^{\circ} 9$.

${ }^{33}$ Sur Plautinus, cf. Rogers 1999, 194-198, qui date sa production entre 160 et 200 (?) ; Names 7, 158-159, avec une datation plus courte établie d'après les formes lisses. 


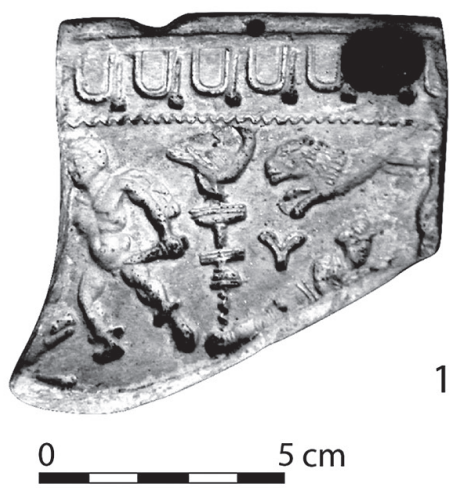

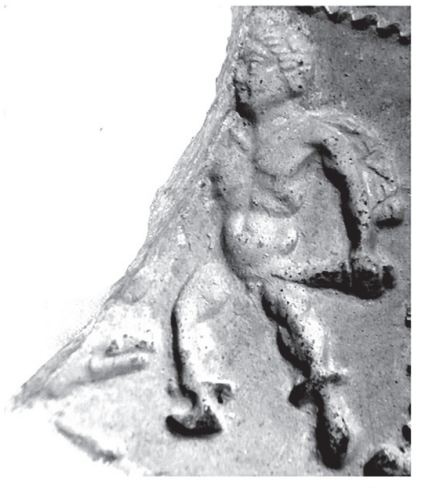

$2 a$

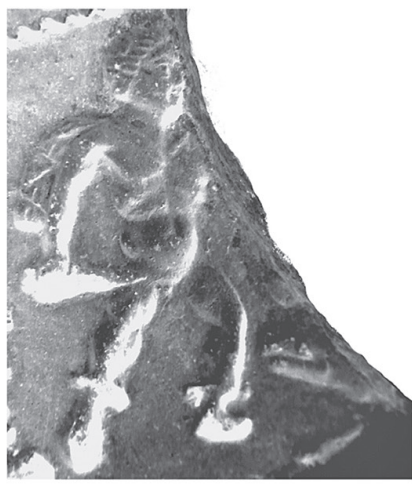

$2 b$

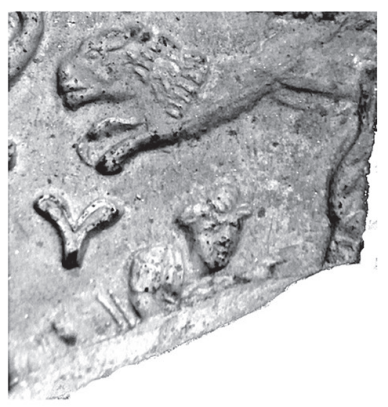

$4 a$

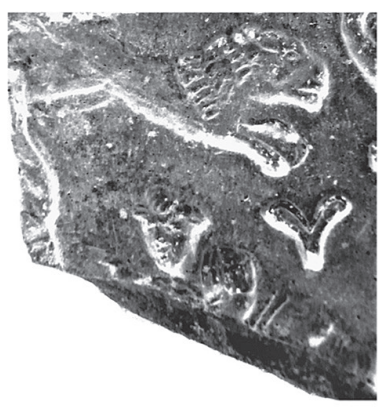

$4 b$

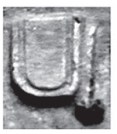

$5 a$

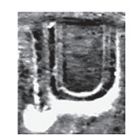

$5 b$
0 $5 \mathrm{~cm}$

Fig. 6. Moule Louvre $\mathrm{n}^{\circ} \mathrm{Cp}$ 4826. 1. vue complète, 2-5. détails : a. photographie directe du moule (a) et positif qui pourrait en être tiré (b), (C) musée du Louvre/András Márton

Fragment d'un moule cylindrique pour la production de bols de forme Drag. 30. Face externe écaillée. Bord limé d'un côté et tranche couverte de traces de colle. Concrétions sur la surface.

Les oves sont délimités en bas par une ligne de perles. Le décor est fermé en partie inférieure par un filet et se compose de panneaux séparés par une ligne de perles dont les intersections sont ornées par une petite couronne $^{34}$ : à gauche, une ménade ; à droite des feuilles antithétiques au-dessus d'un homme tenant une lanterne.

Contrairement à ce que Brian Rogers suggère implicitement, ce moule a servi pour la fabrication de bols à reliefs à paroi cylindrique de forme Drag. 30. Il est classé parmi les œuvres du Potier P-20 identifiées par la petite couronne U124 utilisée dans les intersections des motifs de séparation (fig. 12). ${ }^{35}$ Ce motif semble être sa propre création.

Ce potier est presque exclusivement connu par ses moules. Le seul produit fini connu de lui, attribué par Dr. Joanna Bird, vient de Church Meadow à Ewell (Surrey, Angleterre ; fig. 11. 5-6). Étant donné que tous ses moules et son vase sont de forme Drag. 30, il était peut-être un spécialiste de cette forme.

${ }^{34}$ Motifs figurés : ménade : type comme O368, mais probablement non identique ; homme avec lanterne type O966. Motifs non figurés : ove : B46 ; feuille : J146; petite couronne sur les lignes de perles : U124. Motif non identifié : ligne de perles.
${ }^{35}$ Rogers 1999, 291-292, fig. 77. Son recueil peut être complété par quelques fragments inédits non inventoriés dans la collection du Musée d'Archéologie nationale illustrés sur la figure 12 : $1-2,4,7-8$. inédits ; 3 . Rogers $n^{\circ} 1 ; 5$. Rogers $n^{\circ} 4 ; 6$. Rogers $n^{\circ} 2$; 9. Rogers $n^{\circ} 3\left(\right.$ MAN n $\left.^{\circ} 32743\right)$. 

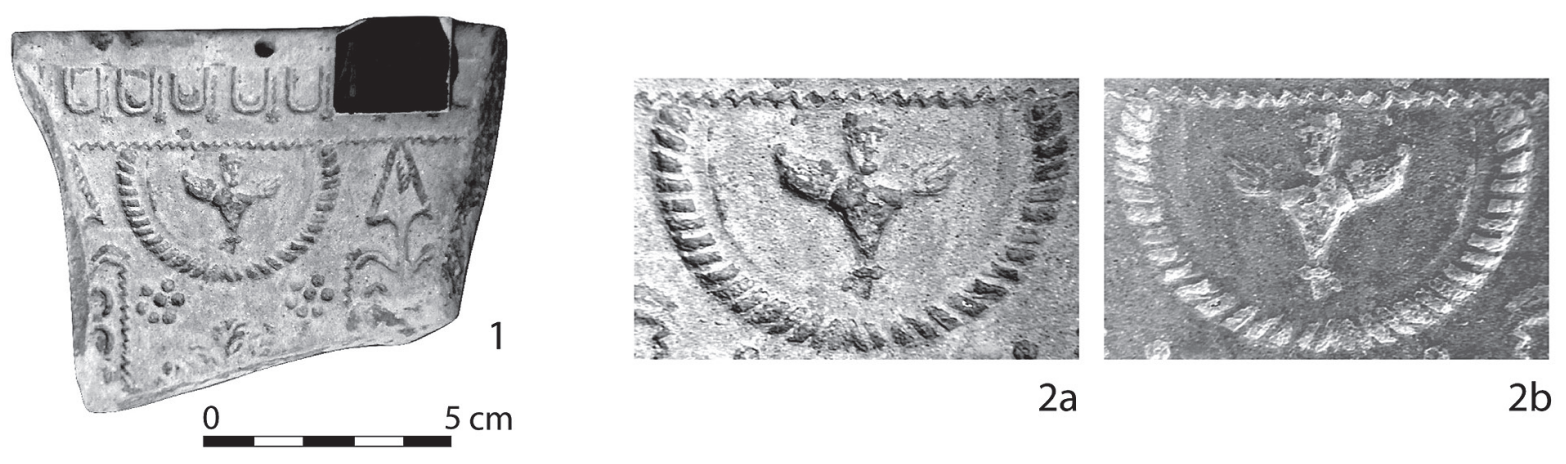

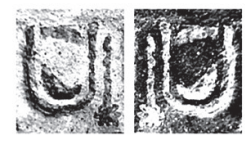

$3 a$

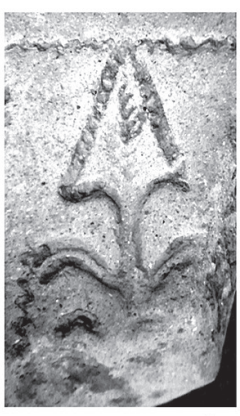

$4 a$

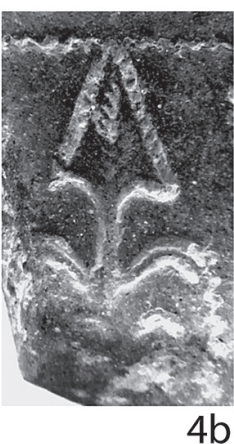

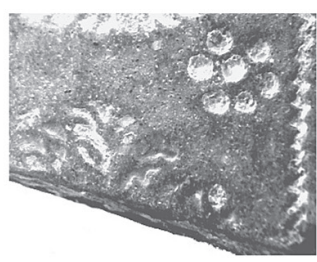

$5 a$

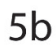

0 $5 \mathrm{~cm}$

Fig. 7. Moule Louvre $n^{\circ} \mathrm{Cp} 4833$. 1. vue complète, 2-5. détails : a. photographie directe du moule (a) et positif qui pourrait en être tiré (b), (C) musée du Louvre/András Márton

Le vase de Church Meadow porte l'ove B105 non attestée sur les moules attribués à ce potier anonyme, mais connue pour Albucius et Paternus II avec lesquels notre potier partage beaucoup, par son style et les poinçons utilisés (fig. 12). ${ }^{36}$

On peut localiser son activité à Lezoux, d'après des critères stylistiques, entre 140 et $160 .^{37}$

9. Fragment de moule pour bols à reliefs de forme Drag. 37 (fig. $1.8 ; 13.1-4$ ).

Inv. : Cp 4835 (H 478). Ancienne collection Campana acquise en 1861 par le musée du Louvre. Dim. : Haut. max. : 9,8 cm. Larg. max. : 13,8 cm. Diam. reconstitué du moule : $28 \mathrm{~cm}$.

Bibl. : Cataloghi Campana, ${ }^{\circ} 35$.

Pâte brun clair, légèrement micacée. Fragment d'un moule hémisphérique avec une encoche, à section triangulaire moulurée, à l'extérieur sous la lèvre. Éclats le long des cassures, concrétions. Traces de cire à l'intérieur et à l'extérieur qui maintenaient une étiquette aujourd'hui perdue.

Oves séparés du décor en panneaux par une ligne incisée : à gauche, restes d'un prédateur quadrupède (ours ?) tourné vers la droite dans un double arceau relié par un astragale avec la ligne de perles séparant les panneaux ; en dessous, une ligne de perles séparant un motif indéchiffrable ; à l'intersection des lignes de perles horizontale et verticale, une tête de lion ; à droite, une nymphe, mal imprimée, tournée vers la gauche et tenant son manteau, estampée dans un double cercle. Dans le champ, des têtes et des queues de dauphins partiellement imprimées. ${ }^{38}$

${ }^{36}$ La liste publiée par G. B. Rogers peut être complétée par B105 pour les motifs non figuratifs et par O117, O345, O450, 0926, O1214. Le fragment de Chuch Meadow montre la même ménade que le moule du Louvre et présente un oiseau du type O2317. Sur un moule inédit du Musée des Antiquités Nationales : rinceau de vigne. Motifs figurés : nymphe : similaire mais pas identique à $\mathrm{O} 347$, ours : O1609 (?) ; dauphin : O2401 (?). Motifs non figurés : ove : B143 ; ligne de séparation sous l'ove comme RoGERs 1999, pl. 89. 3-4 ; astragale R17 (?). Motifs non identifiés : double cercle, double arceau.

${ }^{37}$ Rogers 1999, 292.

${ }^{38}$ Motifs figurés : nymphe : similaire mais pas identique à O347, ours : O1609 (?) ; dauphin : O2401 (?). Motifs non figurés : ove : B143 ; ligne de séparation sous l'ove comme ROGERS 1999, pl. 89. 3-4 ; astragale R17 (?). Motifs non identifiés : double cercle, double arceau. 

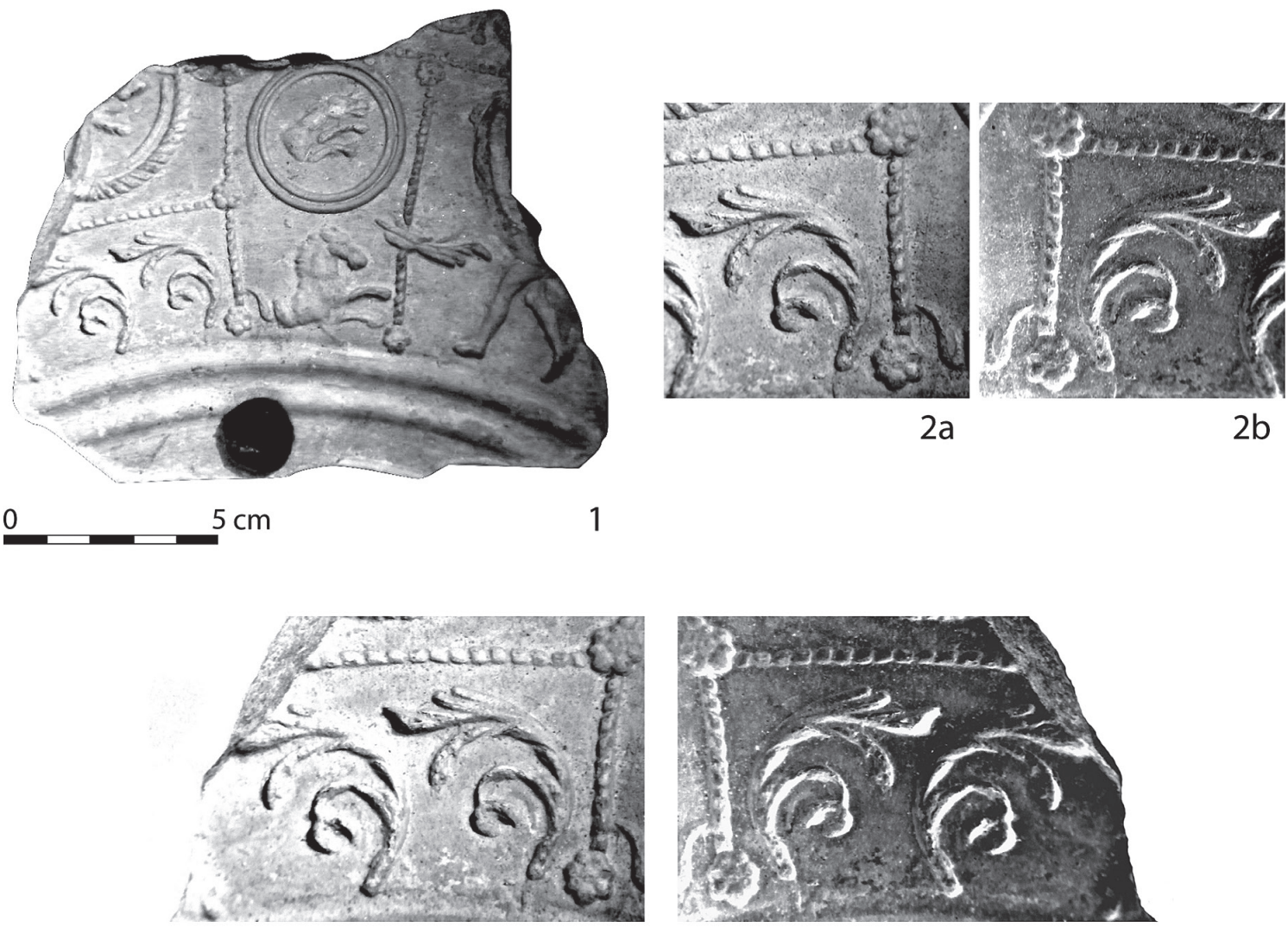

$3 a$
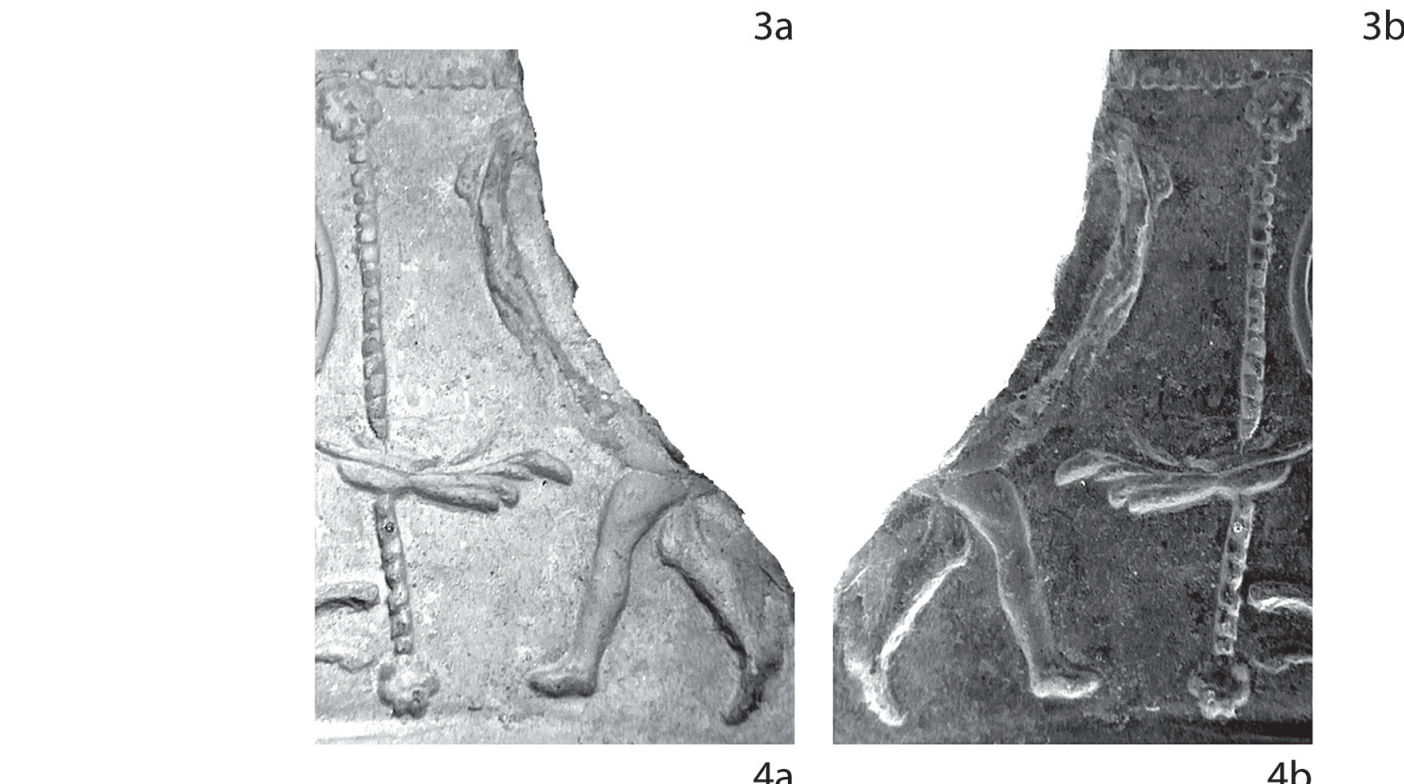

$3 b$

$5 \mathrm{~cm}$

$4 b$

0

$4 a$

Fig. 8. Moule Louvre $\mathrm{n}^{\circ} \mathrm{Cp}$ 4831. 1. vue complète, 2-4. détails : a. photographie directe du moule (a) et positif qui pourrait en être tiré (b), (C) musée du Louvre/András Márton 


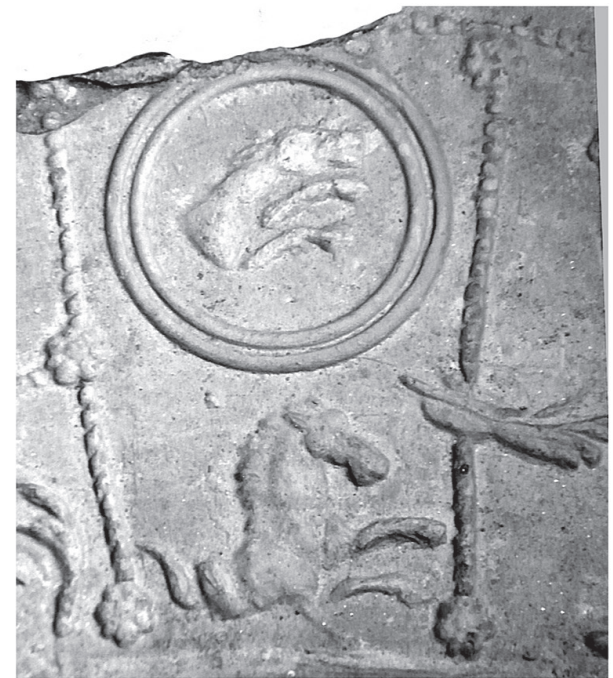

$1 \mathrm{a}$

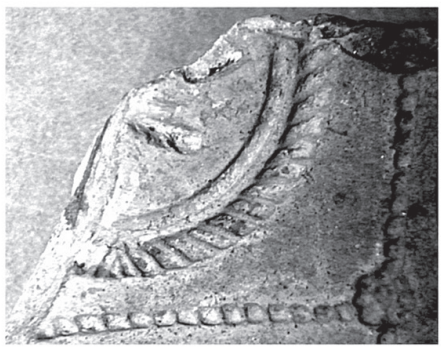

$2 \mathrm{a}$

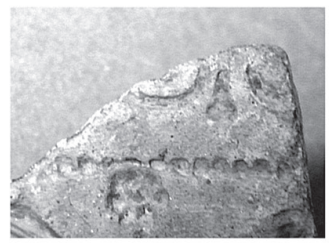

$3 a$

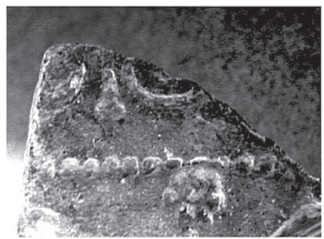

$3 b$

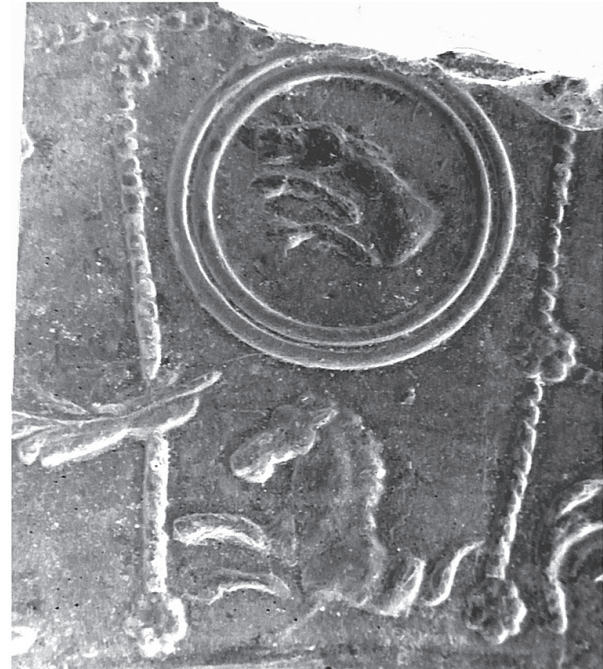

$1 \mathrm{~b}$

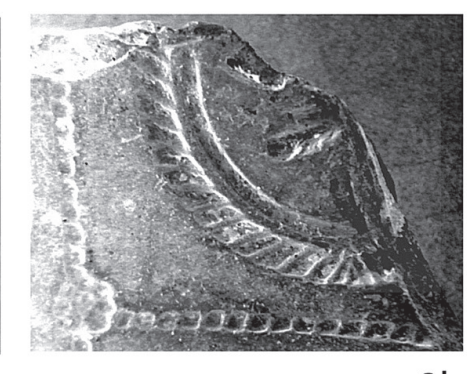

$2 b$

Fig. 9. Moule Louvre ${ }^{\circ} \mathrm{Cp}$ 4831. 1-3. détails : a. photographie directe du moule (a) et positif qui pourrait en être tiré (b), (C) musée du Louvre/András Márton

Le style de ce moule s'inscrit clairement dans l'atelier où Pugnus et Secundus I ont travaillé. Les meilleures comparaisons se trouvent parmi les moules qui sont attribués à Pugnus dans sa phase tardive. ${ }^{39}$ Néanmoins aucun de ces parallèles n'est signé. Le style de Secundus I et le style tardif de Pugnus I sont très proches comme Brian Rogers l'a également observé. ${ }^{40} \mathrm{Il}$ est possible que quelques réattributions soient nécessaires entre les deux potiers. Pugnus I (ou Pugnus II selon la classification des signatures sur sigillée gallo-romaine) était un fabricant de sigillée lisse qui a décoré dans sa phase tardive des bols portant les oves dérivant de l'ove II de Cinnamus dans l'atelier de Secundus. ${ }^{41}$ Le fragment de moule du Louvre a été réalisé à Lezoux, vers $150-170{ }^{42}$

\footnotetext{
${ }^{39}$ Rogers 1999, pl. 89. 2-3, 10-11.

${ }^{40}$ Rogers 1999, 232.

${ }^{41}$ Names 7, 284-285.
} 


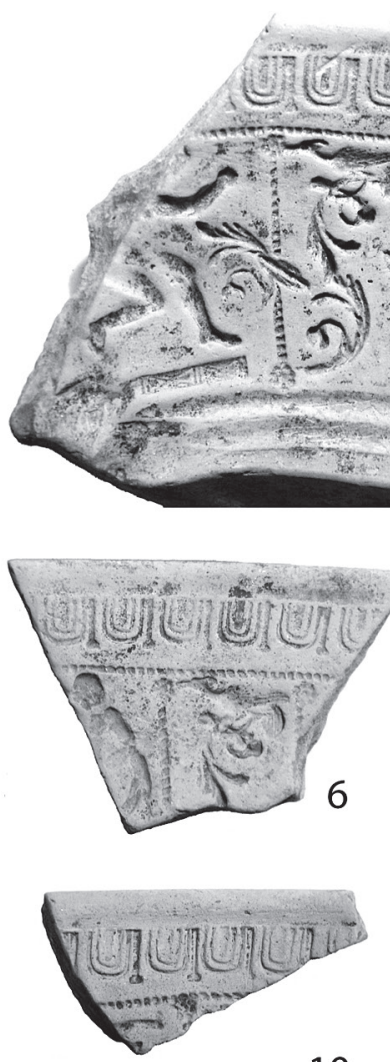

10
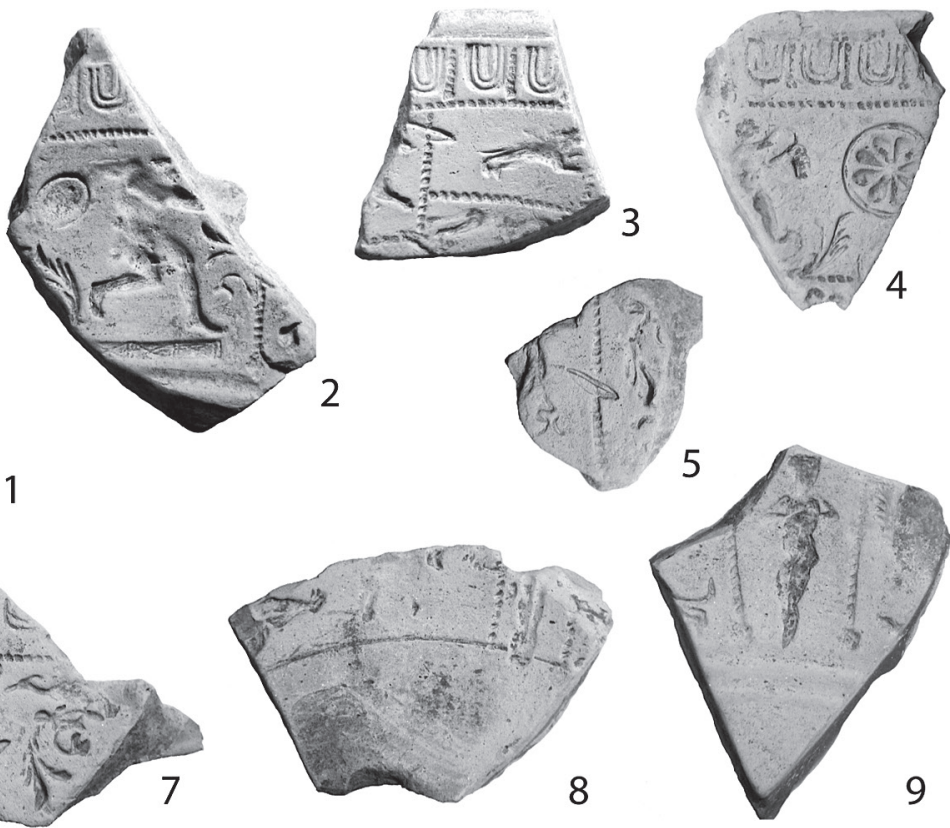

8
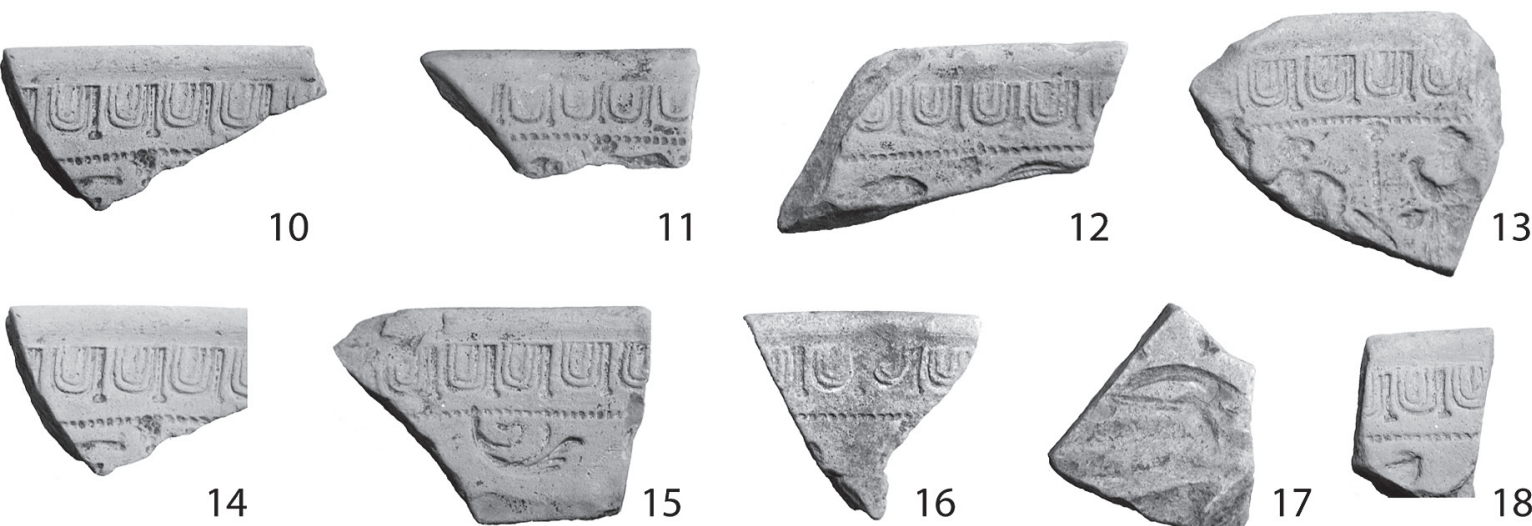

12
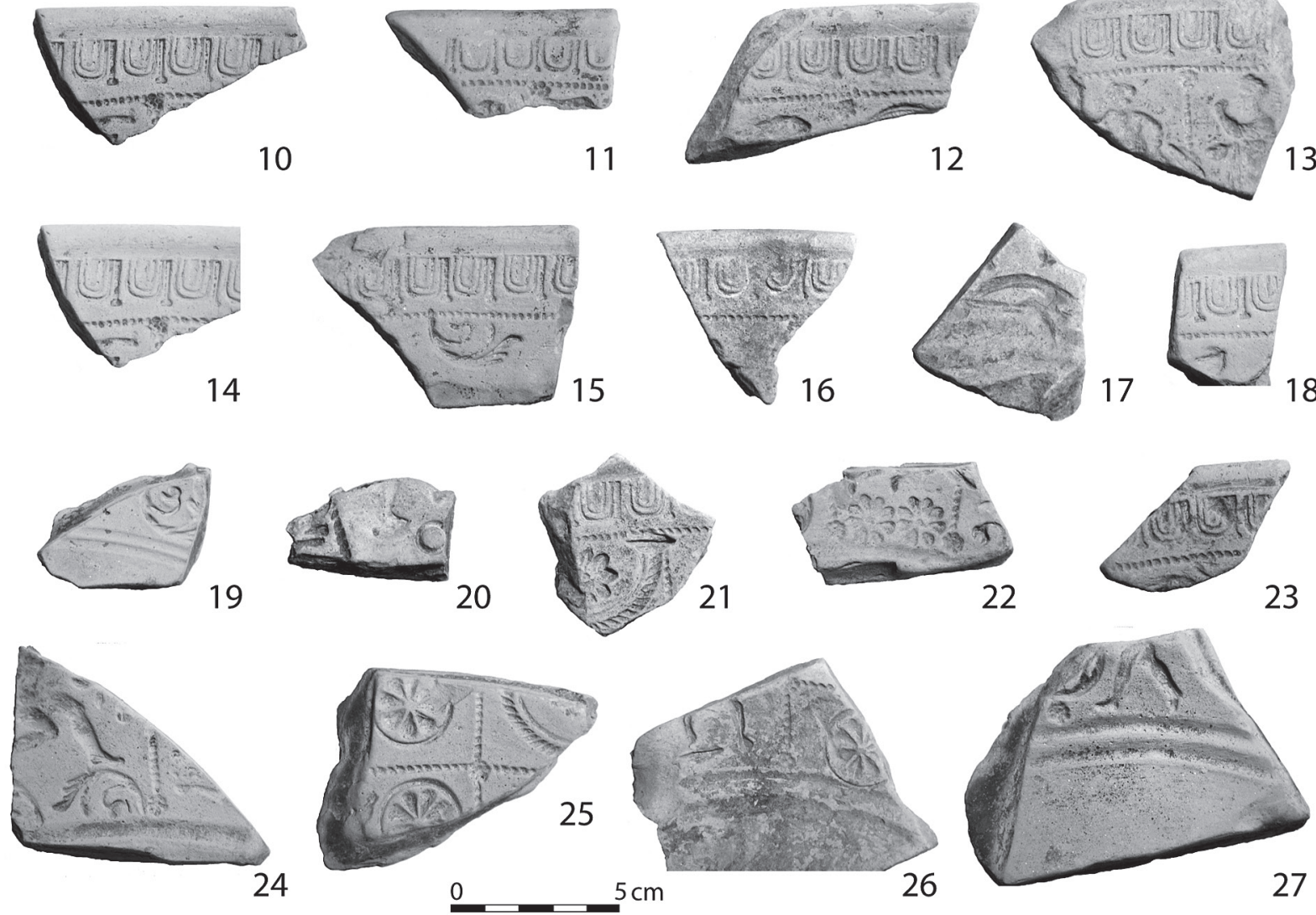

Fig. 10. Fragments de moules inédits de Plautinus dans la collection du Musée d'Archéologie nationale (cf. note 32), (C) Musée d'Archéologie nationale/András Márton 

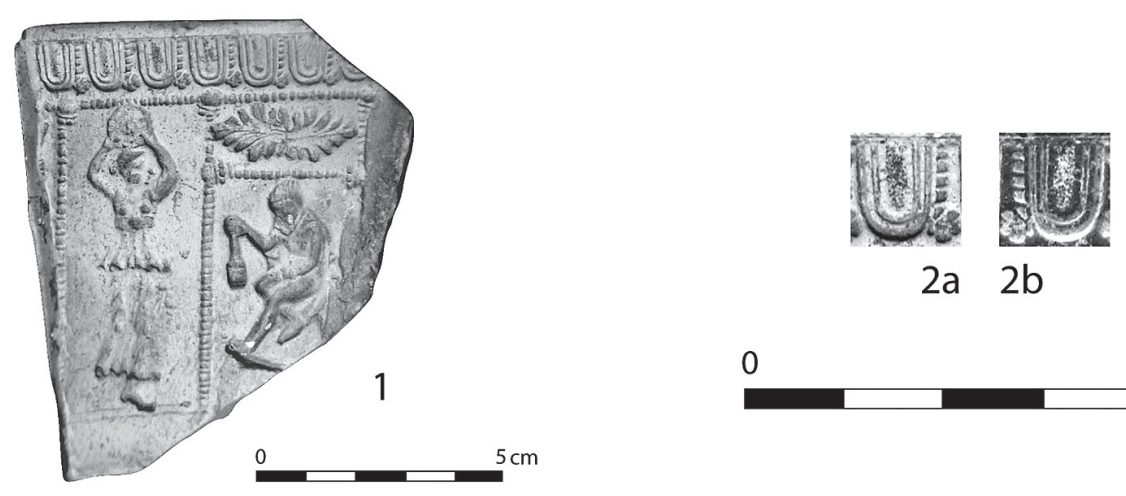

$2 a \quad 2 b$

0

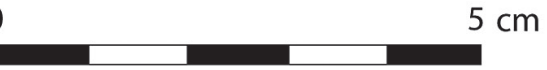

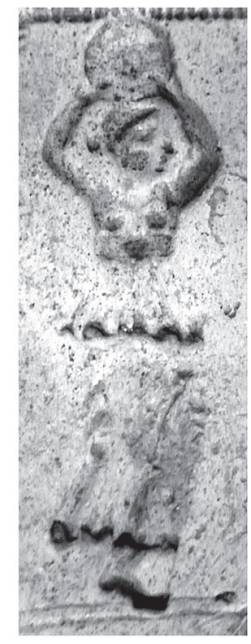

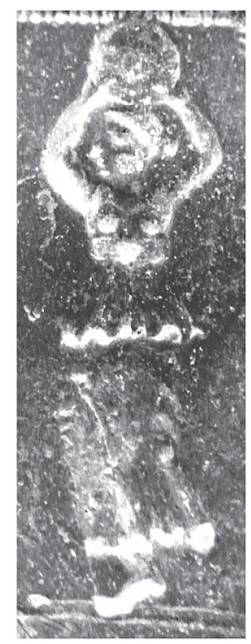

$3 a$ $3 b$
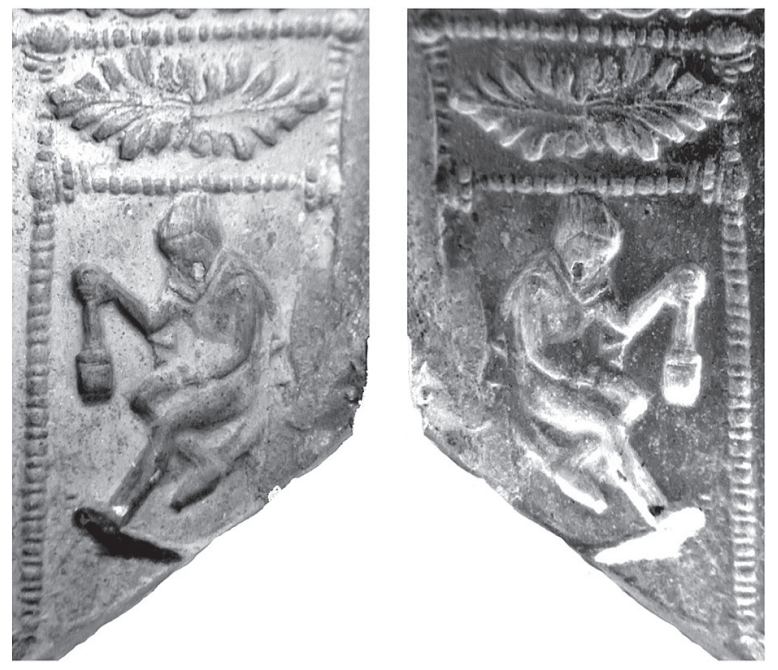

$4 a$
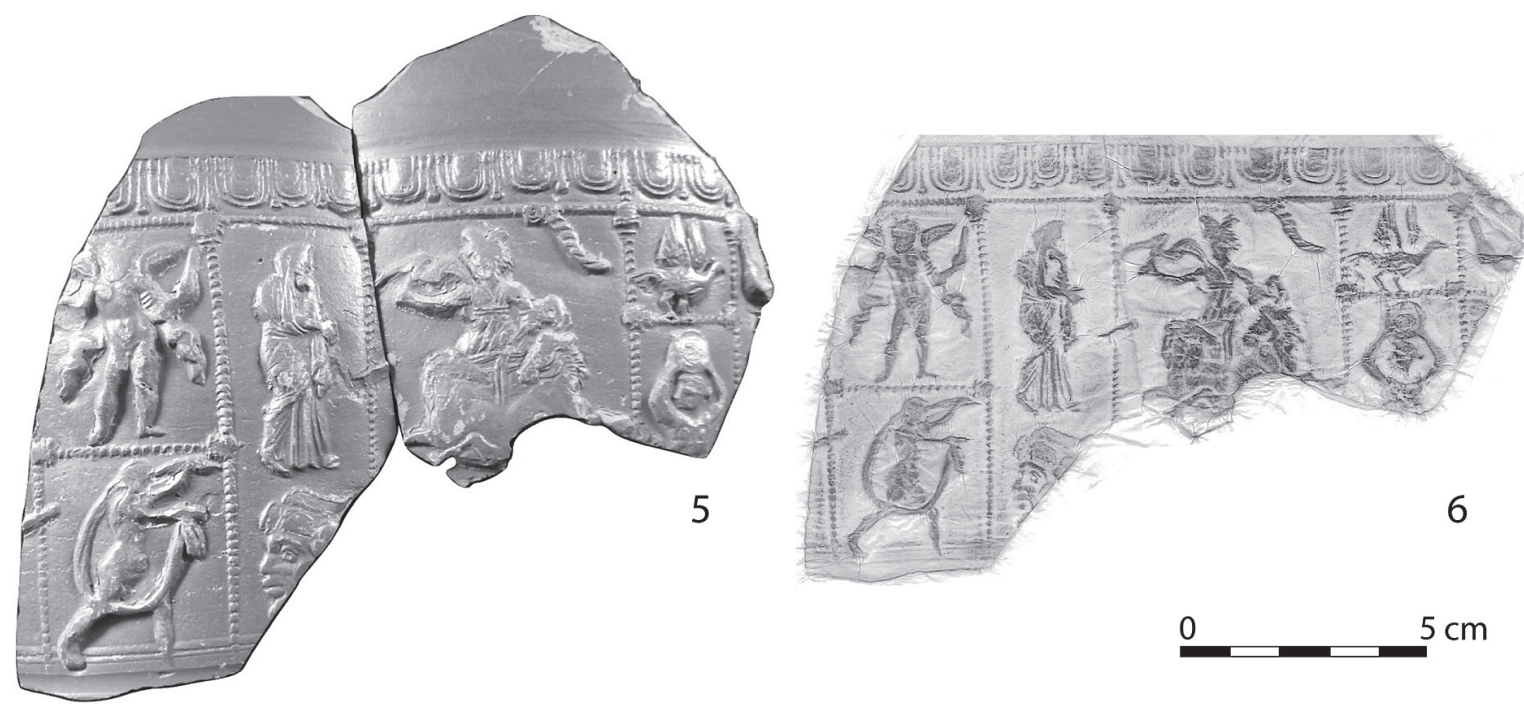

Fig. 11. Moule Louvre n ${ }^{\circ}$ CA 2239. 1. vue complète, 2-4. détails : a. photographie directe du moule (a) et positif qui pourrait en être tiré (b), (c) musée du Louvre/András Márton, 5-6. Bol à relief attribué au Pottier P-20 trouvé à Church Meadow (photo et frottis), courtoisie du Dr. Joanna Bird 


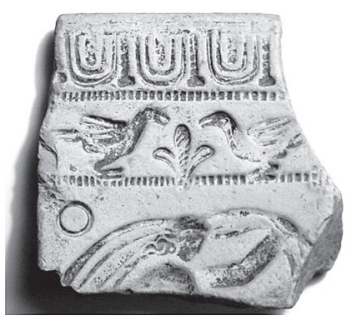

1

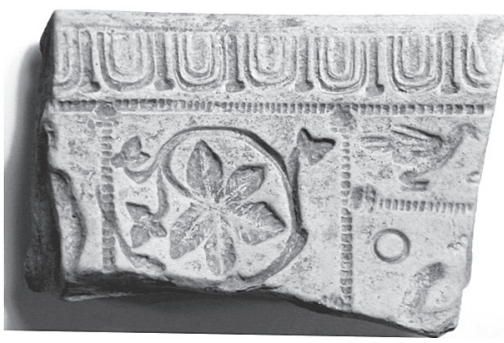

4

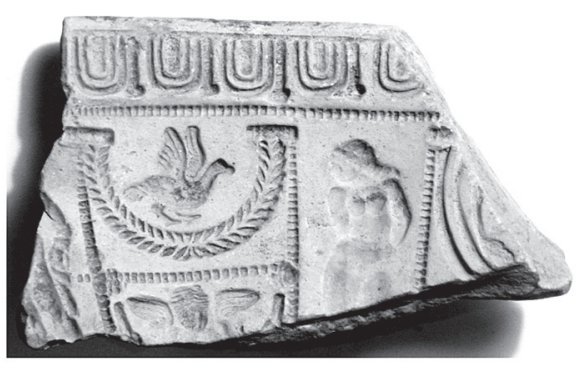

7

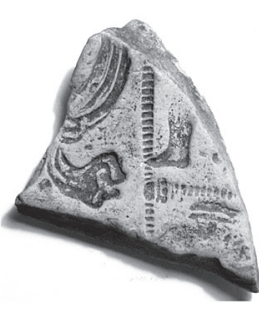

2

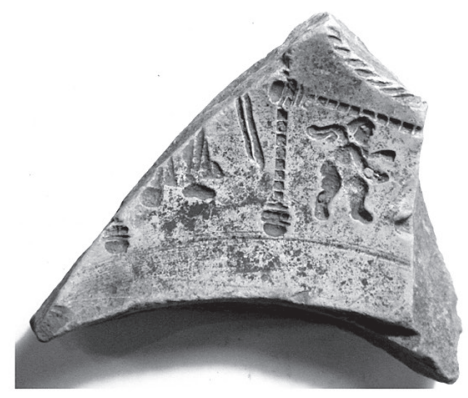

5

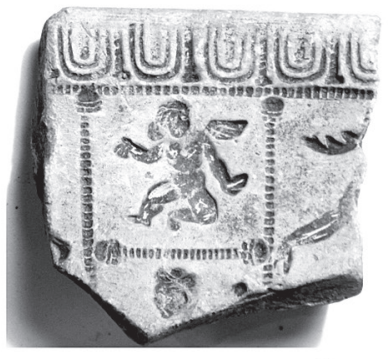

6
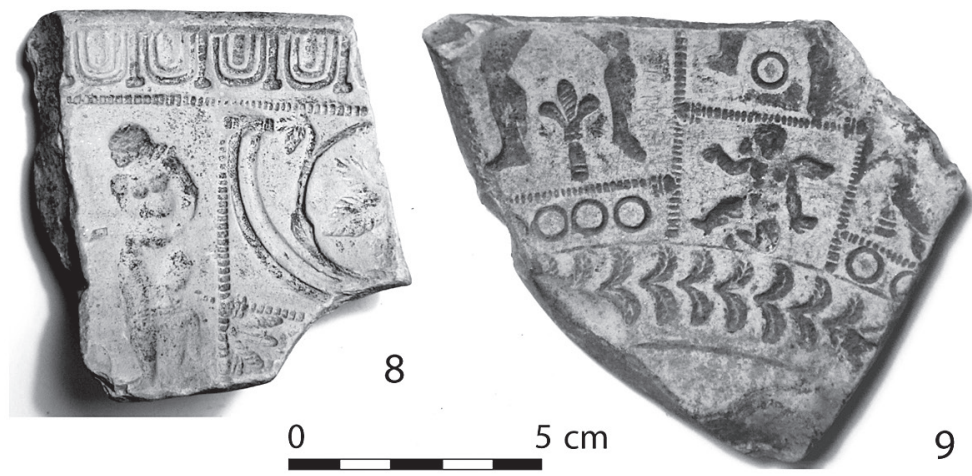

Fig. 12. Fragments de moules attribués au Potier P-20 dans la collection du Musée d'Archéologie nationale (cf. note 35), (C) Musée d'Archéologie nationale/András Márton

10. Fragment de moule pour bols à reliefs de forme Drag. 37 (fig. 1.9 ; 14. 1. 1-4).

Inv. : CA 2238. Prov. inconnue, acquis par le musée du Louvre en 1919. Haut. max. : 10,4 cm. Larg. max. : $10,4 \mathrm{~cm}$. Diam. reconstitué du moule : $28 \mathrm{~cm}$.

Pâte brune, orange-jaunâtre, légèrement micacée, poreuse, pas bien cuite ; à l'intérieur couche cuite gris clair.

Fragment d'un moule hémisphérique avec une encoche sur la paroi externe. Un côté est scié. Oves délimités par une ligne de perles, décor en métopes séparées par des lignes de perles fermées par une petite couronne : à gauche, une figure de Vénus anadyomène, au centre un composition florale estampée deux fois l'une sur l'autre avec un décalage, et à droite les restes d'une même Vénus. ${ }^{43}$

Le style n'est pour le moment pas attribué à un potier précis, mais le décorateur de ce moule a travaillé dans l'entourage d'Albucius et de Paternus.

On peut localiser la création du moule à Lezoux, d'après des critères stylistiques et l'apparition de l'ove B106 dans le décor vers 150-175.

${ }^{43}$ Motifs non figurés : Ove : B106 (Albucius, Paternus); composition florale : L3 (Carantinus, Iuliccus, Libertus I, Quintilius) Motif figuré : Vénus : O277 (Catusas, Censorinus, Doeccus, Iullinus,
Libertus Ib). Motifs non identifiés : ligne des perles ; terminaison sur les motifs de démarcation. 


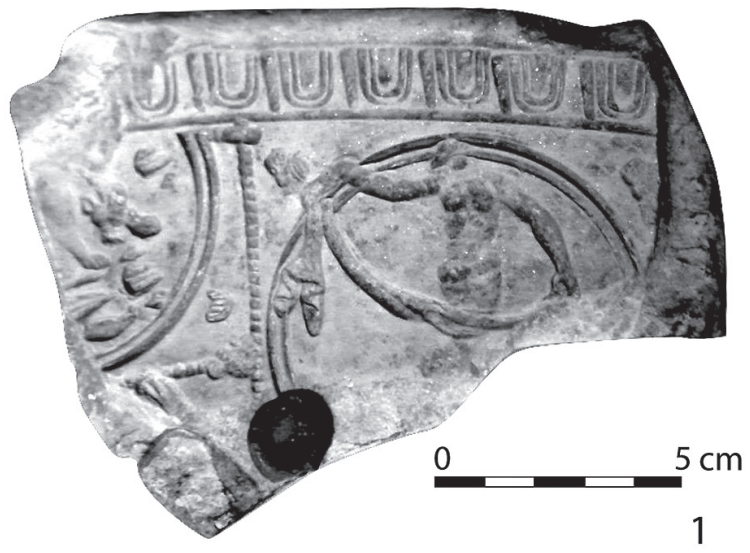

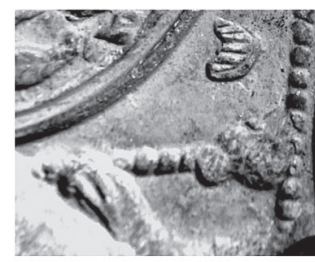

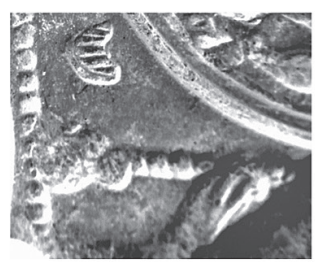

$2 a$
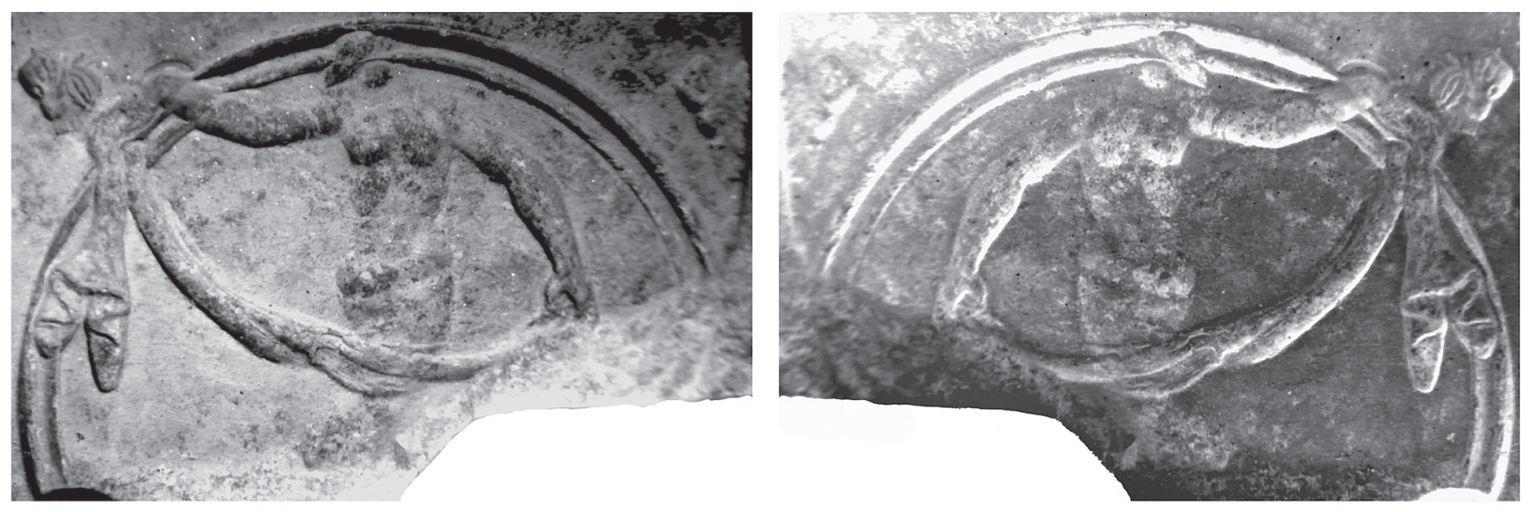

$3 a$

$3 b$

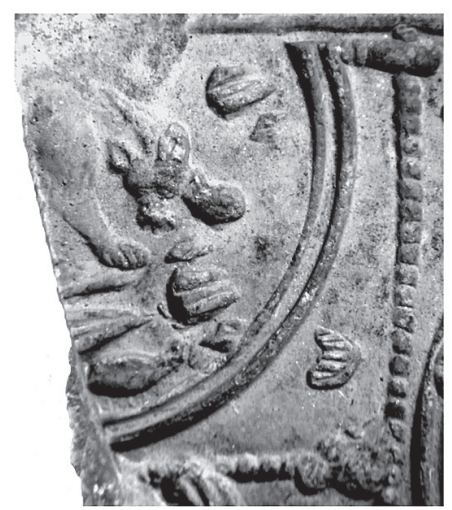

$4 a$

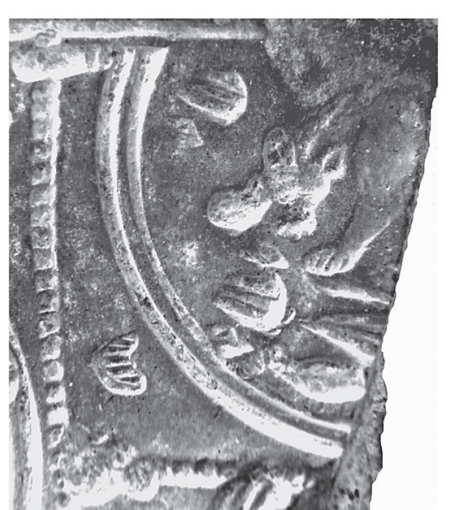

$4 b$

Fig. 13. Moule Louvre $n^{\circ} \mathrm{Cp}$ 4835. 1. vue complète, 2-4. détails : a. photographie directe du moule (a) et positif qui pourrait en être tiré (b), (C) musée du Louvre/András Márton. 

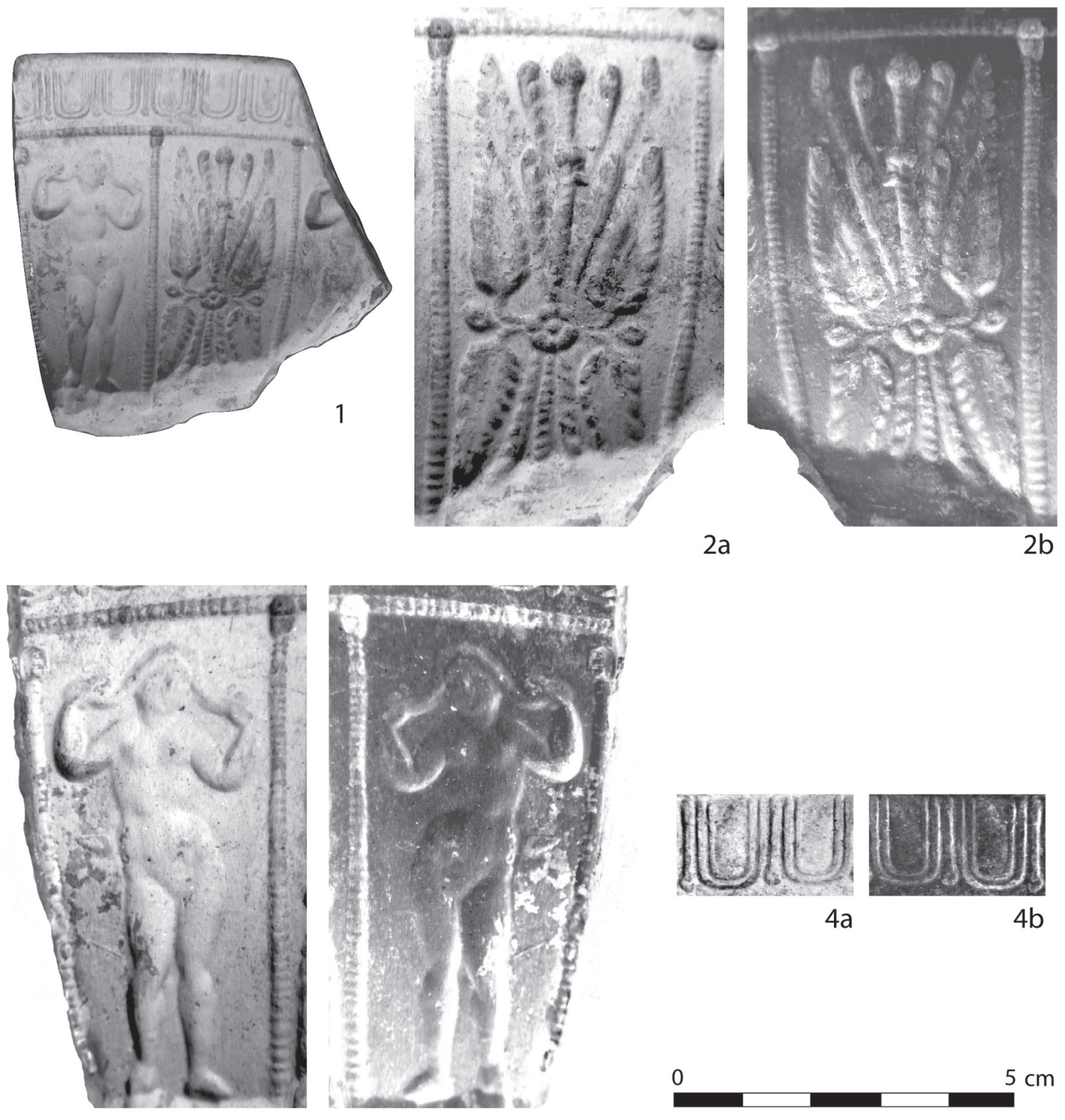

$3 a$

$3 b$

Fig. 14. Moule Louvre ${ }^{\circ}$ CA 2238. 1. vue complète, 2-4. détails : a. photographie directe du moule (a) et positif qui pourrait en être tiré (b), (C) musée du Louvre/András Márton 

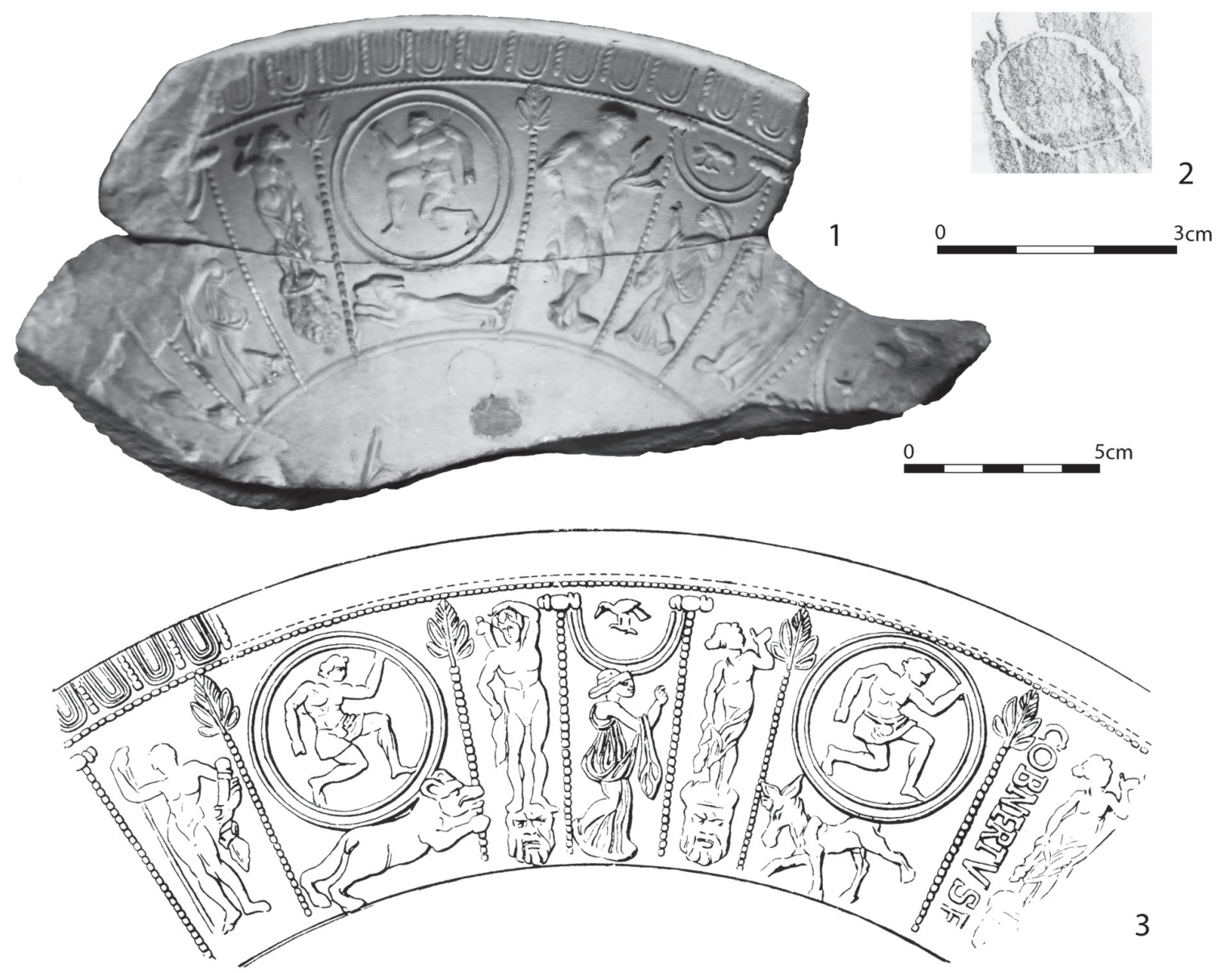

Fig. 15. Moule Louvre ${ }^{\circ}$ ED 1420-1421. 1. Vue complète et 2. détail,

(C) musée du Louvre/András Márton. 3. moule signé par Cobnertus III (d'après MANUEL 2005, Taf. 32. 1)

11. Fragment de moule pour bols à reliefs de forme Drag. 37 (fig. $1.10 ; 13.1-2$ ).

Inv. ED 1420-1421 (N 4366). Découvert à Rheinzabern, 1816. Ancienne collection Durand acquise en 1825 par le musée du Louvre. Haut. max. : 13,3 cm. Larg. max. : $24 \mathrm{~cm}$. Diam. reconstitué du moule : $24 \mathrm{~cm}$.

Argile brun clair avec de très petites inclusions calcaires. Des taches noircies sur le côté extérieur. Traces d'usure sur la face supérieure de la lèvre.

Recollé à partir de deux fragments. Un troisième est signalé dans l'inventaire, mais il est aujourd'hui perdu : il s'agit sans doute de la lacune en haut à droite qui devait compléter la partie supérieure de la figure du guerrier armé d'une lance et une partie de la composition en double cercle.

La frise d'oves est délimitée en bas par une ligne de perles. Le décor en métopes séparées par des lignes de perles, est fermé en bas par une ligne horizontale : à gauche, restes de Pan; ensuite, motif non conservé dans un double arceau surmontant une femme drapée ; Vénus sur un masque ; un coureur nu à droite dans un double cercle ; en dessous, un chien courant vers la gauche ; Apollon ; un oiseau tourné vers la droite dans un double arceau ; en dessous, une femme drapée ; un homme tenant une lance conservé jusqu'au buste. Ensuite la métope du coureur se répète, bien que partiellement lacunaire. Les doubles arceaux sont liés aux motifs de séparation par un astragale, les lignes de perles verticales avant et après le grand cercle double sont couronnées par une feuille. ${ }^{44}$

Au fond du moule, en dehors de la zone décorée, un « $O »$ inscrit après la cuisson (fig. 15. 2).

${ }^{44}$ Motifs : Ove : E40; Vénus sur masque : M51; Apollon : M73 ; femme drapée : M246; oiseau : T250; chien : comme T147 mais probablement pas identique ; feuille quadruple : P88 ; feuille double : K19 ; double cercle : K85 (?) ; astragale : O96. 


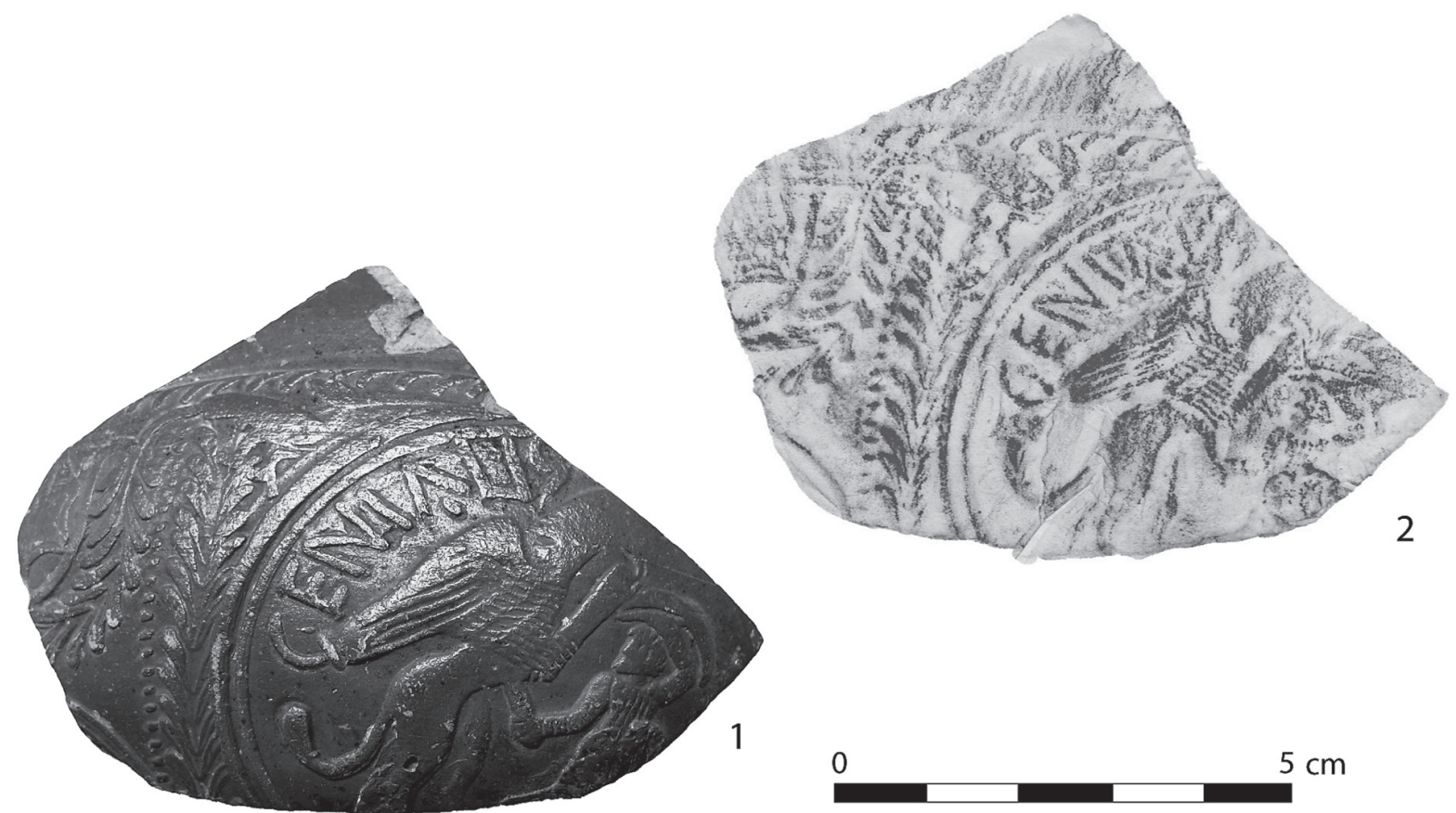

Fig. 16. Fragment du bol à reliefs Louvre n ${ }^{\circ}$ A 6254 (photo et frottis), @ c musée du Louvre/Florence Specque et András Márton

Le style de ce moule est clairement identifiable à la série A de Cobnertus III de Rheinzabern. Un vase signé par ce potier, trouvé à Rheinzabern, porte en effet un décor très proche (fig. 15. 3). ${ }^{45} \mathrm{Il}$ est si proche. Seuls les animaux sous les médaillons ornés d'un coureur sont différents, que l'on ne peut pas exclure que ce vase complète le décor perdu de ce même moule. Un fragment de vase avec une composition identique provient de Brigetio (Szőny) ; mais le dessin publié de ce fragment ne permet pas d'affirmer qu'il provienne de ce moule. ${ }^{46}$ La marque après cotturam « $O \gg$ peut correspondre à l'initiale de l'utilisateur ou du propriétaire du moule. ${ }^{47}$

Cobnertus III est parmi les premiers potiers de Rheinzabern ; la série A de sa production peut-être datée entre $155 / 160$ et $180 .^{48}$

En plus de ces fragments de moules, un tesson signé mérite une attention particulière, non seulement parce qu'il nous permet d'associer un nom à un potier anonyme mais également parce qu'il nous donne des renseignements précieux sur des ateliers de potiers de l'époque de Trajan à Lezoux.

\section{Fragment d'un bol à reliefs de forme Drag. 37 (fig. 16).}

Inv. : CA 6254. Découvert à Lyon dans la nécropole de Trion ; Ancienne collection Guimet. Haut. : 5,9 cm ; Larg. : $8,1 \mathrm{~cm}$.

Bibl. : BÉMONT 1977a, 190-191, nº 283.

Argile couleur saumon avec un peu de micas et de calcaire. Vernis rouge orangé, imparfaitement cuit, mat à l'intérieur, brillant avec des taches mates à l'extérieur. Correspond aux caractéristiques de la fabrique 3.

${ }^{45}$ Th. Manuel (Bearb.) : Die Dekorationsserien der Rheinzaberner Reliefsigillata. Materialien zur römisch-germanischen Keramik 14. Bonn 2005, Taf. 32. 1.
${ }^{46}$ GY. JUHÁSZ : A brigetioi terra sigilláták (Die Sigillaten von Brigetio). DissPann II.3. Budapest 1935, 93, n ${ }^{\circ}$ 13, pl. XXII. 13.

${ }^{47}$ Cf. HaAlebos - MeEs - Polak 1991, 81.

${ }^{48}$ Mees 2002, 328 ; Names 3, 67-68. 

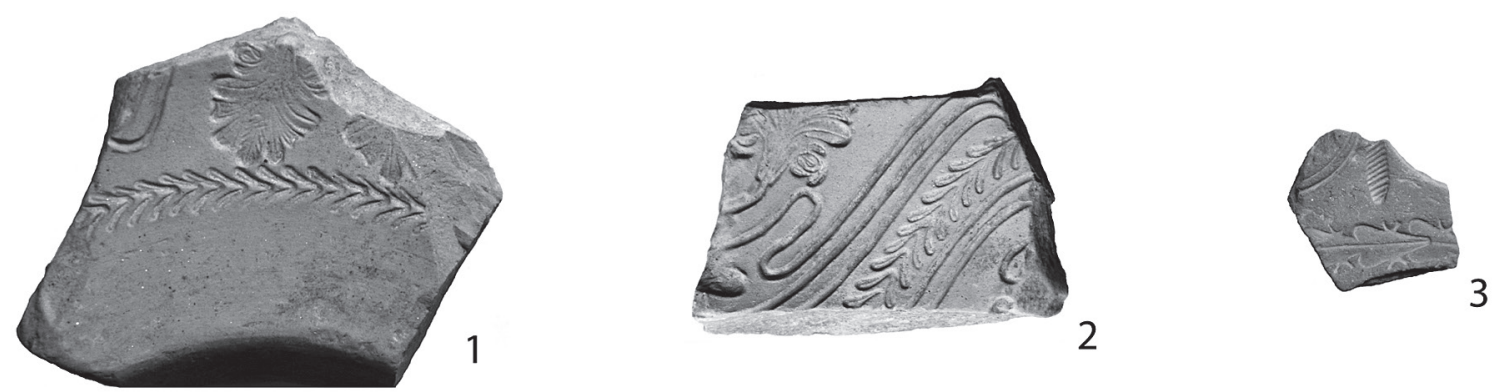

2
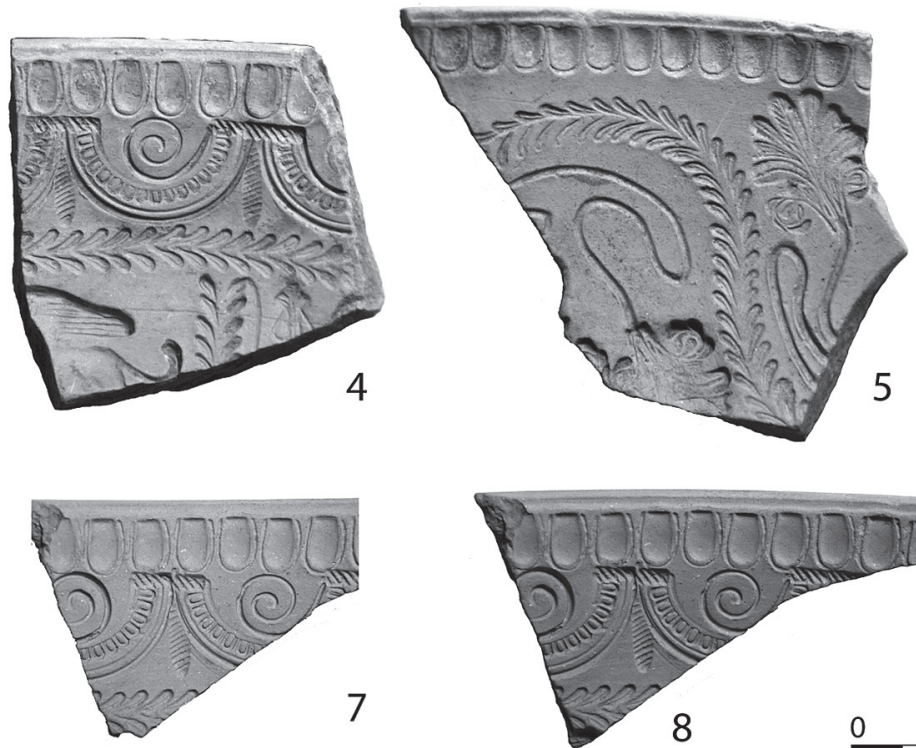

7
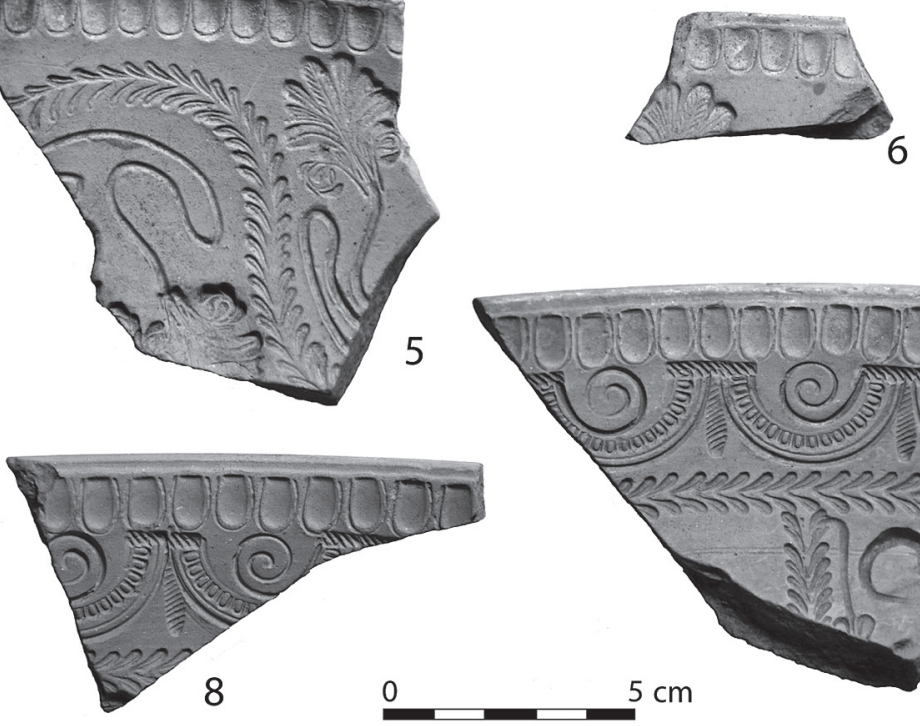

Fig. 17. Fragments des moules attribués au Genialis = Potier P-5 dans la collection du Musée d'Archéologie nationale (cf. note 57), (C) Musée d'Archéologie nationale/András Márton

Le décor est organisé en panneaux ou pseudo-panneaux et est délimité en haut par une rangée de feuilles partiellement effacée lors du tournage du vase. ${ }^{49}$ Au centre, dans un médaillon formé par un double cercle, une scène de griffomachie accompagnée par une signature de potier de grande taille : GENIALIS. A gauche du médaillon, une ligne de feuilles verticales couronnée par un oiseau à tête retournée vers l'arrière puis une ligne de perles ; à gauche, un fragment d'une décoration florale composée d'une guirlande de feuilles doubles et d'une grande feuille ; au dessus, le reste d'un double cercle ou d'un double arceau. ${ }^{50}$

La qualité de l'argile et le verni ainsi que le style du décor inscrivent sans ambigüité ce vase dans la production lezovienne de l'époque de Trajan.

Seule la signature a été publiée par Colette Bémont, sans le décor qui l'accompagnait et elle n'a pas été incluse dans le nouveau recueil des signatures. ${ }^{51}$ Elle est particulièrement intéressante car il s'agit d'une attestation précoce d'une grande signature emblématique, à vocation «publicitaire », dans le décor d'une sigillée moulée lezovienne. Les véritables grandes marques (parfois en cartouche) apparaissent peu avant le milieu du II ${ }^{\mathrm{e}}$ siècle (vers 140). Auparavant seuls quelques ateliers phares ont utilisé des marques de grande taille dans le décor. ${ }^{52}$ Parmi eux,

${ }^{49}$ Tilhard 2004, 445, nº 682, pl. 190. 682, probablement aussi attribuable à Genialis.

${ }^{50}$ Motifs non figurés : ligne de perles : A3 (?) ; double feuille : G285 ; grande feuille : J4. Motifs figurés : griffon : R.4075 (le tesson du musée du Louvre est l'exemple le plus complet de ce motif).
${ }^{51}$ Dr. Brenda Dickinson nous a aimablement informés que cette marque n'a pas été incluse car les auteurs n'ont pas pu examiner ce fragment et ils n'ont disposé ni d'une reproduction du décor ni d'une attestation de la signature ailleurs.

${ }^{52}$ Delage 2004, 152, 265, note Titos, OfLiberti (Libertus Ic de G. B. Rogers, 100-120), Butrio, AustriOF. 


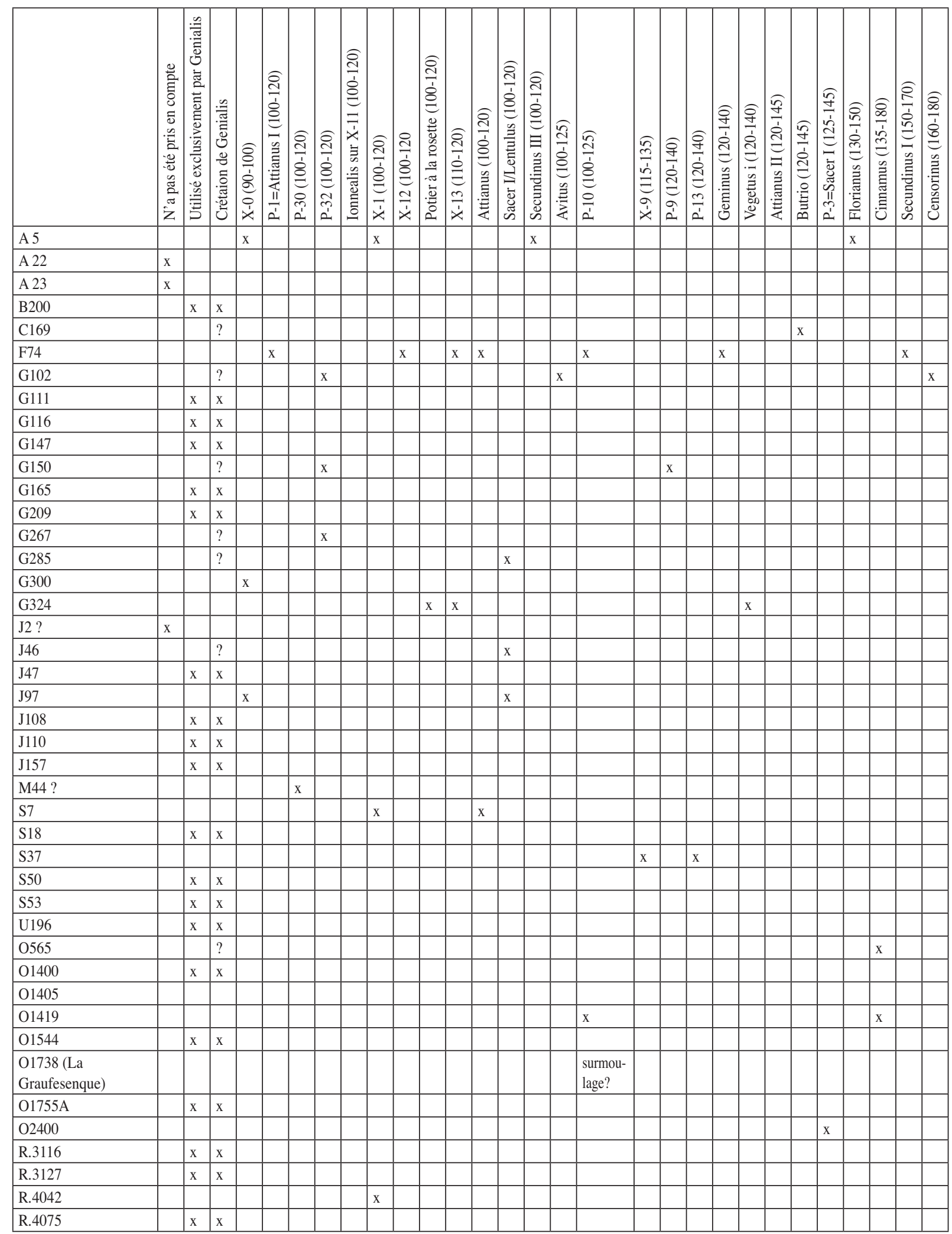

Fig. 18. Récapitulatif des poinçons utilisés par Genialis 


\begin{tabular}{|c|c|c|c|c|c|c|c|c|c|c|c|c|c|c|c|c|c|c|c|c|c|c|c|c|c|c|c|c|c|}
\hline & 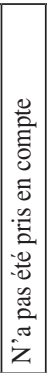 & 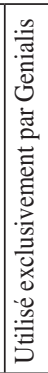 & 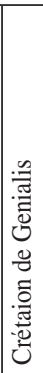 & 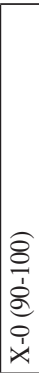 & 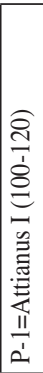 & 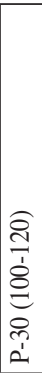 & 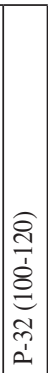 & 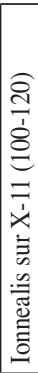 & 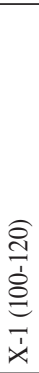 & 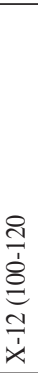 & 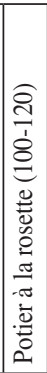 & 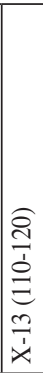 & 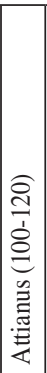 & 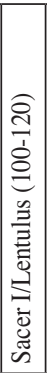 & 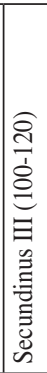 & 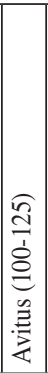 & 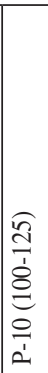 & 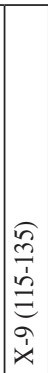 & 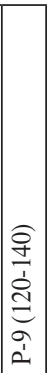 & 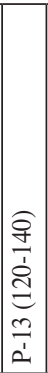 & 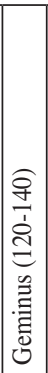 & 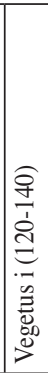 & 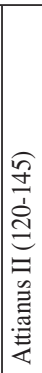 & 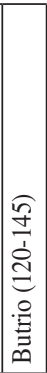 & 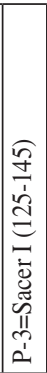 & 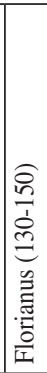 & 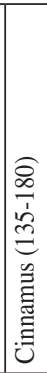 & 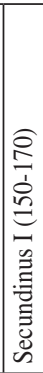 & 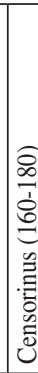 \\
\hline R.4092 & & & & & & & & & $\mathrm{x}$ & & & & & & & & & & & & & & & & & & & & \\
\hline $\begin{array}{l}\text { Deux feuilles palmées } \\
\text { (Tilhard 2004, } \\
\text { pl. 190.675) }\end{array}$ & & & & & & & & & & & & & & & & & & & & & & & & & & & & & \\
\hline $\begin{array}{l}\text { Petite personnage } \\
\text { avec épée }\end{array}$ & & $\mathrm{x}$ & $\mathrm{x}$ & & & & & & & & & & & & & & & & & & & & & & & & & & \\
\hline $\begin{array}{l}\text { Apollon sur piedestale } \\
\text { (Tilhard 2004, } \\
\text { pl. 190.675) }\end{array}$ & & $x$ & $x$ & & & & & & & & & & & & & & & & & & & & & & & & & & \\
\hline $\begin{array}{l}\text { Poinçons communs } \\
\text { avec Genialis }\end{array}$ & & & & 3 & 1 & 1 & 3 & 1 & 4 & 1 & 1 & 2 & 2 & 3 & 1 & 1 & 2 & 1 & 1 & 1 & 1 & 1 & 1 & 1 & & 1 & 2 & 1 & 1 \\
\hline
\end{tabular}

Fig. 18. Récapitulatif des poinçons utilisés par Genialis

seul Titios précède Genialis ; Libertus i $^{53}$ est à peu près contemporain ; les autres sont plus récents. Ce changement reflète sans doute une évolution des pratiques dans les ateliers et des stratégies commerciales. A l'époque flavienne, on observe un remplacement des vases carénés (Drag. 29) par des bols hémisphériques (Drag. 37) plus rapides à produire. Cela s'accompagne d'une transformation de l'organisation de la production et du partage des tâches dans les ateliers dont l'un des symptômes est que l'écriture passe progressivement, mais non exclusivement, des mains du potier tourneur des vases décorés à celles du potier décorateur ou du responsable de l'officine. ${ }^{54} \mathrm{Le}$ début du $\mathrm{II}^{\mathrm{e}}$ siècle est également la période où la sigillée non grésée est progressivement remplacée par un vernis grésé permettant à la production de Lezoux d'entrer sur le marché à longue distance et d'être de plus en plus compétitive face aux ateliers de Gaule méridionale. ${ }^{55}$ La quantité de la production augmente, la qualité s'améliore et l'aire de diffusion s'agrandit. Tout cela a sans doute été accompagné par une transformation profonde des ateliers et de la production ainsi que du mode et des stratégies de commercialisation. C'est dans ce contexte qu'il faut appréhender l'apparition de ce nouveau type de marquage signalant visiblement aux acheteurs la création de l'atelier de Genialis et surtout permettant de distinguer sa marchandise sur les marchés.

Mais qui était Genialis $?^{56}$ Les poinçons utilisés et le style du décor permettent de l'identifier avec un potier anonyme appelé par Brian Rogers le Potier P-5 (fig. 17). ${ }^{57}$ En regardant les poinçons utilisés par Genialis (fig. 18), on remarque tout de suite qu'un grand nombre est attesté seulement pour sa production et semble être sa propre

${ }^{53}$ B. R. Hartley - B. M. Dickinson : Names on Terra Sigillata. An Index of Makers' Stamps \& Signatures on Gallo-Roman Terra Sigillata (Samian Ware). 5.: L to Masclus I. London 2009, 57 ; Libertus I de G. B. Rogers 1999, 157-158.

${ }^{54}$ Delage 2004, 146-147.

${ }^{55}$ R. Delage : Les structures de production des ateliers de potiers à Lezoux du $\mathrm{I}^{\mathrm{er}}$ au IV $\mathrm{IV}^{\mathrm{e}}$ s., reflets de l'évolution des stratégies commerciales et de l'organisation du travail. In : L'artisanat romain : évolutions, continuités et ruptures (Italie et provinces occidentales). Dir. : M. Polfer. Monographie instrumentum 20. Montagnac 2001, $117-136,121$

${ }^{56}$ Genialis est parmi les cognomens les plus populaires, il signifie joyeux, de bonne humeur, mais aussi nuptial, génial, cf. I. Kajanto : The Latin Cognomia. Helsinki 1965, 260.
${ }^{57}$ Sur le potier, cf. S. E. CoTTAM : A study of the work of Dr. Felix Oswald on the Oswald-Plicque collection of Samian pottery, now at Durham University. Durham theses, Durham University 1991, 57, pl. IV. 5, prov. de Lezoux, fragment d'un bol avec oves (B200) accompagné de G267 ; Rogers 1999, 269-271, pl. 121 ; TILHARD 2004, 445-447, n ${ }^{\text {os }} 675,682-683,693-694,702-703$, pl. 190-191, 675, 682, 192-193. 683, 693-694, 702-703 ; NORMAND 2009, 41, Décor 11, fig. 3 .

Les moules illustrés par G. B. Rogers peuvent être complétés par trois fragments non inventoriés dans la collection du Musée d'Archéologie nationale illustrés sur la figure 17 (lors de notre visite à Saint-Germain-en-Laye nous n'avons pas pu voir les fragments Rogers $\left.n^{\circ} 1,3,6,9-11,14-15\right): 1$. inédit cf. Rogers $n^{\circ} 2 ; 2$. inédit appartient à Rogers $n^{\circ} 2 ; 3$. inédit ; 4. Rogers $n^{\circ} 5 ; 5$. Rogers $n^{\circ} 2$; 6. inédit appartient ? à Rogers $n^{\circ} 2 ; 7-8$. Appartiennent à Rogers $n^{\circ}$ 5. 9 . Rogers $\mathrm{n}^{\circ} 5$ (?). 
création (18 sur 45), que 7 autres poinçons peuvent être également de son invention car leur première attestation est documentée sur les vases qui sont lui attribués. En effet, c'est un innovateur fier de ses nouveaux poinçons comme le prouve sa marque mise en évidence à côté de la griffomachie réalisée avec les poinçons qu'il a créés. Genialis est probablement issu de l'entourage du Potier X-0 (voir $n^{\circ} 2$ ) avec qui il partage un certain nombre de poinçons communs et qui était le prédécesseur du Potier X-1 avec lequel Genialis partage également un certain nombre de poinçons. Étonnement peu de ces poinçons ont été repris par des potiers postérieurs.

Sa production a été retrouvée à Besançon, Poitiers, Lyon et en Gaule Belgique (?). Cette distribution est conforme à ce que l'on attend pour la sigillée lezovienne à l'époque de Trajan. ${ }^{58}$ On ne peut que formuler des hypothèses sur le peu d'influence de cet atelier sur les décorateurs postérieurs. Cette nouvelle organisation, qui se reflète dans la grande marque, était peut-être un peu trop précoce pour le marché et ne s'est pas révélée si prolifique que prévu. Il est également possible que ce soient des raisons liées aux aléas de la vie personnelle du potier qui ont conduit à un arrêt de sa production et à une disparition de l'usage d'une bonne partie de ses poinçons. Il est également envisageable que certains de ces poinçons n'étaient pas bien adaptables, par leur sujet ou leur style, aux décors de l'époque d'Hadrien et des Antonins. Ils pouvaient aussi être moins bien utilisables pour réaliser des décors à reliefs plus prononcés qu'à l'époque de Trajan et c'est pourquoi ils n'ont pas été repris.

Comme cette grande signature l'annonce, son entreprise était ambitieuse, impliquant sans doute l'activité de plusieurs potiers, probablement également de plusieurs décorateurs, mais elle est pour le moment mal connue. Une analyse exhaustive des vases à reliefs de cette période permettrait de connaître les divers décorateurs et de comprehende leurs relations ainsi que le rôle joué par l'atelier de Genialis.

\section{CONCLUSION}

Cette petite série conservée dans la collection du musée du Louvre fournit des renseignements primaires sur la production de sigillée et enrichit le répertoire des poinçons. Plusieurs centres sont représentés : La Graufesenque $\left(n^{\circ} 1\right)$, Les Martes-de-Veyre ( $\left.{ }^{\circ} 3\right)$, Lezoux ( $\left.n^{\circ} 4-9\right)$ et Rheinzabern $\left(n^{\circ} 11\right)$.

G(.) At(.) Pas(.) est un potier tardif de La Graufesenque ( $\left.n^{\circ} 1\right)$, hélas la décoration de ses œuvres est peu connue. Son activité correspond à une période marquée par le retrait progressif de la sigillée de La Graufesenque des marchés à longue distance.

Presque contemporain, le Potier X-0 de Lezoux $\left(\mathrm{n}^{\circ} 2\right)$ pourrait avoir travaillé dans le centre de La Graufesenque. Il était le prédécesseur du Potier X-1. Genialis ( $\left.n^{\circ} 12\right)$, d'après les poinçons qu'il a utilisés, était également issu de leur entourage. Le tesson du Louvre permet de donner un nom au Potier X-5 resté jusqu'ici anonyme et d'enrichir le répertoire des poinçons qui lui sont attribués. L'activité de ce potier novateur, peut-être fondateur d'un atelier, correspond à une phase d'expérimentation à Lezoux alors que la sigillée non grésée est remplacée par la production grésée plus brillante qui introduit ensuite la sigillée de la Gaule centrale sur les marchés lointains. ${ }^{59}$

Plusieurs moules appartiennent à la phase suivante (120-140) marquée par le début de la commercialisation à grande échelle de la sigillée de Gaule centrale sur les marchés à longue distance. La production de l'atelier de Quintilianus ( $n^{\circ} 5-6$ ) en est un fossile directeur. ${ }^{60}$

Le reste des moules de Gaule centrale date de la phase de la plus grande diffusion de cette sigillée. Parmi les potiers représentés, on ne connaît presque pas les produits finis de Plautinus ( $\left.{ }^{\circ} 7\right)$, en revanche on connaît une belle série de ses moules. Plusieurs décorateurs ont travaillé dans l'entourage d'Aduocisus $\left(n^{\circ} 4\right)$ ou d'Albucius et de Paternus ( $n^{\circ} 8$ et 10$)$ qui ont bénéficié d'une distribution très vaste. ${ }^{61}$ Le Potier P-20 $\left(n^{\circ} 8\right)$ semble être un spécialiste de la fabrication de moules pour des bols à paroi cylindrique Drag. 30. Sa production semble modeste et peu diffusée. Pugnus $\left(n^{\circ} 9\right)$ était un fabricant de sigillée lisse qui a décoré dans sa phase tardive des moules pour bols hémisphériques dans l'atelier de Secundus. ${ }^{62}$

\footnotetext{
${ }^{58}$ Delage 1998, 282-284, fig. 4.

${ }^{59}$ Cf. en Pannonie à Vindobona, Weber-Hiden 1996, 32.

${ }^{60}$ Sur le rôle de l'atelier de Quintilianus, cf. Delage 1991 , 284. Et voir le cas de Vindobona, WEBER-HIDEN 1996, 33, pl. 36. 1-8.
}

${ }^{61}$ Weber-Hiden 1996, 34.
${ }^{62}$ Names 7, 284-285. 
Cobnertus ( $\left.n^{\circ} 11\right)$ était l'un des premiers décorateurs de Rheinzabern. Son style atteste une influence lezouvienne, il pourrait avoir passé quelques années de formation à Lezoux avant d'établir son activité indépendante dans le nouveau centre prometteur de Rheinzabern. La production issue de ses moules est nombreuse et distribuée partout dans la zone d'influence de Rheinzabern, notamment en Pannonie. ${ }^{63}$

\section{BIBLIOGRAPHIE}

BÉMONT 1977a

BÉMONT 1977b

Cataloghi Campana

Delage 1998

Delage 2004

GAULtier et al. 2018.

HaAlebos - Mees - PolaK 1991

MeEs 1995

MEES 2002

Names 1

Names 3

Names 7

NORMAND 2009

ROGERS 1974

ROGERS 1999

STANFIELD - SIMPSON 1990

TILHARD 2004

WEBER-HIDEN 1996
= C. BÉMONT : Marques sur céramiques sigillées au Musée du Louvre. MEFRA 89/1 (1977) 169-218.

= C. BÉmont : Moules de gobelets ornés de la Gaule centrale au Musée des antiquités nationales. Gallia suppl. 33. Paris 1977.

= Cataloghi del Museo Campana. Catalogo della classe IV. : Opere in plastica o terre cotte italiche, greche e romane con un saggio della scultura etrusca in alabastro e pietre indigene. Serie 11. [Rome 1859].

$=$ R. Delage : Première approche de la diffusion des céramiques sigillées du centre de la Gaule en Occident romain. SFECAG Actes du Congrès d'Istres. Marseille 1998, 271-318.

$=$ R. Delage : L'écrit en « représentation ». Les marques de grande format au sein des décors sur sigillée du Centre de la Gaule. Gallia 61 (2004) 145-152.

= F. Gaultier - L. Haumesser - A. Trofimova : Un rêve d Italie. La collection du marquis Campana. Catalogue d'exposition. Paris 2018.

= J. K. HaAlebos - A. W. MeES - M. PolaK : Über Töpfer und Fabrikaten verzierter Terra-sigillata des ersten Jahrhunderts. AKorr 21 (1991) 79-91.

= A. W. MeEs : Modelsignierte Dekorationen auf Südgallischer Terra Sigillata. Forschungen und Berichte zur Vor- und Frühgeschichte in Baden-Württemberg. Stuttgart 1995.

= A. W. MEES : Organisationsformen römischer Töpfer-manufacturen am Beispiel von Arezzo und Rheinzabern. Römisch-Germanisches Zentralmuseum Monographien 52. Mainz 2002.

= B. R. HARTLEY - B. M. Dickinson : Names on Terra Sigillata. An Index of Makers' Stamps \& Signatures on Gallo-Roman Terra Sigillata (Samian Ware). 1. : A to Axo. London 2008.

= B. R. HARTLEy - B. M. Dickinson : Names on Terra Sigillata. An Index of Makers' Stamps \& Signatures on Gallo-Roman Terra Sigillata (Samian Ware). 3. : Certianus to Exsobano. London 2008.

= B. R. Hartley - B. M. Dickinson : Names on Terra Sigillata. An Index of Makers' Stamps \& Signatures on Gallo-Roman Terra Sigillata (Samian Ware). 7. : P to RXEAD. London 2011.

$=$ T. NoRmAND $:$ Sigillées moulées du centre de la Gaule au Musée des Beaux-Arts et d'Archéologie de Besançon. In : Recueil d'études portant sur la céramique Sigillée du Centre de la Gaule. Sous la dir. de R. Delage. Lezoux 2009, 35-134.

= G. B. Rogers : Poteries sigillées de la Gaule centrale. I. : Les motifs non figurés. Gallia Supp. 28. Paris 1974.

= G. B. Rogers : Poteries sigillées de la Gaule centrale. II. : Les potiers. Lezoux 1999.

= J. A. StAnFiEld - G. Simpson : Les potiers de la Gaule centrale. Paris 1990.

= J.-L. Tilhard : Les céramiques sigillées du Haut-Empire à Poitiers d'après les estampilles et les décors moulés. SFECAG Supp. 2. Marseille 2004.

= I. WEBER-HIDEN : Die reliefverzierte Terra sigillata aus Vindobona. 1. : Legionslager und canabae. Vienne 1996.
${ }^{63}$ Par. ex. Weber-Hiden 1996, 34, pl. 86 ; Z. Hantos : A rheinzaberni reliefdíszes terra sigillaták pannoniai forgalmáról

Acta Archaeologica Academiae Scientiarum Hungaricae 70, 2019
(Über den Verkehr reliefverzierter Terra Sigillaten aus Rheinzabern in Pannonien). ArchÉrt 130 (2005) 105-135, 117-118. 